\title{
Review Article \\ Effect of Filler Shape on the Thermal Conductivity of Thermal Functional Composites
}

\author{
Changqing Liu, ${ }^{1}$ Mao Chen, ${ }^{1}$ Dongyi Zhou, ${ }^{1}$ Dezhi Wu, ${ }^{1}$ and Wei Yu ${ }^{2}$ \\ ${ }^{1}$ School of Mechanical and Energy Engineering, Shaoyang University, Shaoyang, Hunan 422001, China \\ ${ }^{2}$ College of Engineering, Shanghai Polytechnic University, Shanghai 201209, China \\ Correspondence should be addressed to Wei Yu; yuwei@sspu.edu.cn
}

Received 16 June 2017; Accepted 10 August 2017; Published 30 October 2017

Academic Editor: Jingchao Zhang

Copyright (c) 2017 Changqing Liu et al. This is an open access article distributed under the Creative Commons Attribution License, which permits unrestricted use, distribution, and reproduction in any medium, provided the original work is properly cited.

\begin{abstract}
With the rapid development of electronic industry, heat dissipation issue becomes more and more important. Thermal functional composites (TFCs) are usually binary composites, filled with thermal conductive additives (nanomaterials) in matrix, and the composites show good thermal performance. The theoretical and experimental results show that the filler shape is one of the most important but easily overlooked factors. In this article, we provide a systematic review of the effect of the filler shape on the thermal conductivity of TFCs, and the heat transfer enhancement based on synergistic effect is also summed up. Finally, the future trends of further improving thermal properties of TFCs are predicted.
\end{abstract}

\section{Introduction}

Thermal management issues are very important in the electronic industry and other related fields [1-5]. Thermal functional composites (TFCs) are usually binary composites, filled with thermal conductive additive in matrix, forming an efficient thermal conductive pathway. TFCs are an effective way to solve the heat dissipation for electronic components. TFCs mainly include thermal interface materials, nanofluids, phase-change materials, and thermal conductive plastics. Thermal interface materials (TIMs) are filled between the heat sources and heat sinks, replacing the air in solid contact gap. As a result, the overall heat transfer resistance for heat dissipation process is significantly decreased [6-8]. Nanofluids are solid-liquid suspensions, which consist of the thermal conductive nanoparticles and the base liquid [9-11]. Phasechange materials (PCMs) are applied in the Li-ion battery packs, which can prevent temperature from rising beyond the normal operating range and improve performance [1214]. Thermal conductive plastics are the composites filled with high thermal conductivity additive in plastics matrix $[15,16]$. For the above TFCs, the parameter of thermal conductivity is the most important factor, and how to improve their thermal conductivity is still one of the biggest challenges.
Currently, to enhance heat transfer performance of TFCs has become a research hotspot, and a large amount of papers have emerged [17-24]. The influence factors for thermal conductivity of TFCs are mainly from the following several aspects: filler shape, functional treatment technique, volume fraction, type of base fluid, directional alignment technique, interfacial thermal resistance [25-27], and so forth. Among them, the filler shape is one of the most important but easily overlooked factors. The shape contains particles, nanowires, nanotubes, nanorods, nanosheets, nanoribbons, and the formation of complementary structure between different morphologies. In this article, we provide a systematic review of the effect of filler shape on the thermal conductivity of TFCs.

\section{Effect of Filler Shape on the Thermal Conductivity of TFCs}

For the effect of filler shape on the thermal conductivity of TFCs including $0 \mathrm{D}$ particles, $1 \mathrm{D}$ nanowires, 2D nanosheets, and other shapes, these theoretical and experimental results showed that the filler with unique shape was easy to form thermal conductivity network, resulting in higher thermal conductivity. 


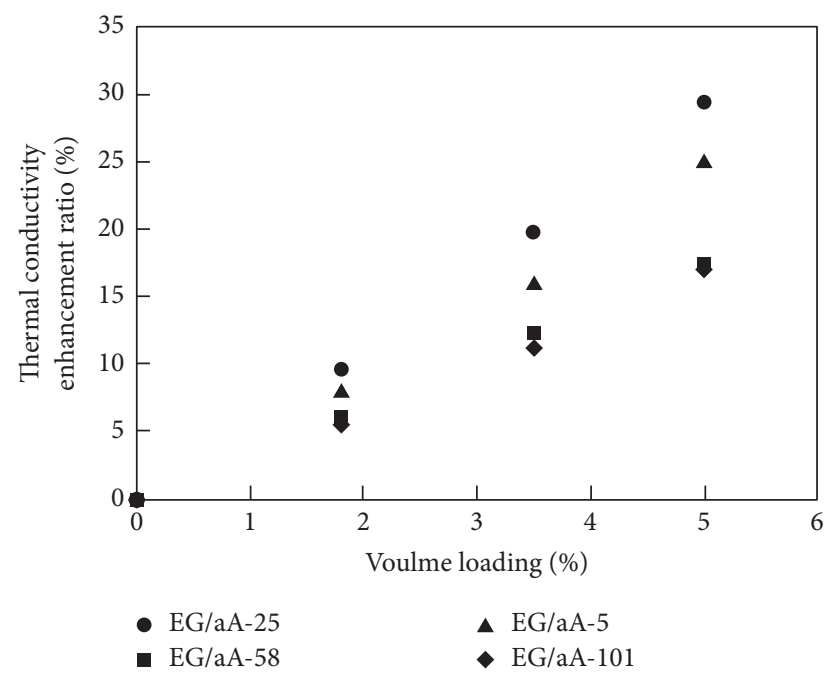

FIGURE 1: Thermal conductivity enhancement ratio for the nanofluids with different alumina nanoparticles in EG. aA-5 (particle size: $302 \mathrm{~nm}$ ), aA-25 (particle size: $60.4 \mathrm{~nm}$ ), aA-58 (particle size: $26.0 \mathrm{~nm}$ ), and aA-101 (particle size: $15.0 \mathrm{~nm}$ ). EG: ethylene glycol [31].

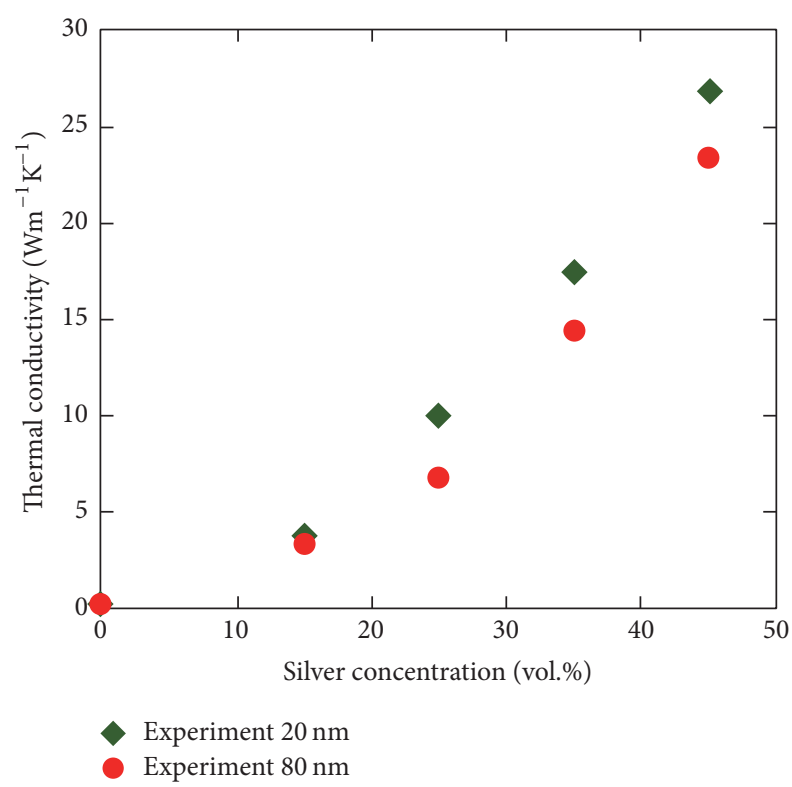

FIGURE 2: Experimentally measured thermal conductivity of epoxysilver nanocomposites [34].

2.1. OD Particles. Particles with the good dispersion properties in matrix attract great attention as the first kind of additive in binary composites for thermal conductivity enhancement. For the intrinsic thermal conductivity of particles, the theoretical calculations show that it is lower than that of corresponding bulk materials due to the scattering of the main carriers of energy (phonon) at the particle boundary [28-31]. The intrinsic thermal conductivity of particles decreases with decreasing size, especially when the size is smaller than the phonon mean free path. Subsequently,

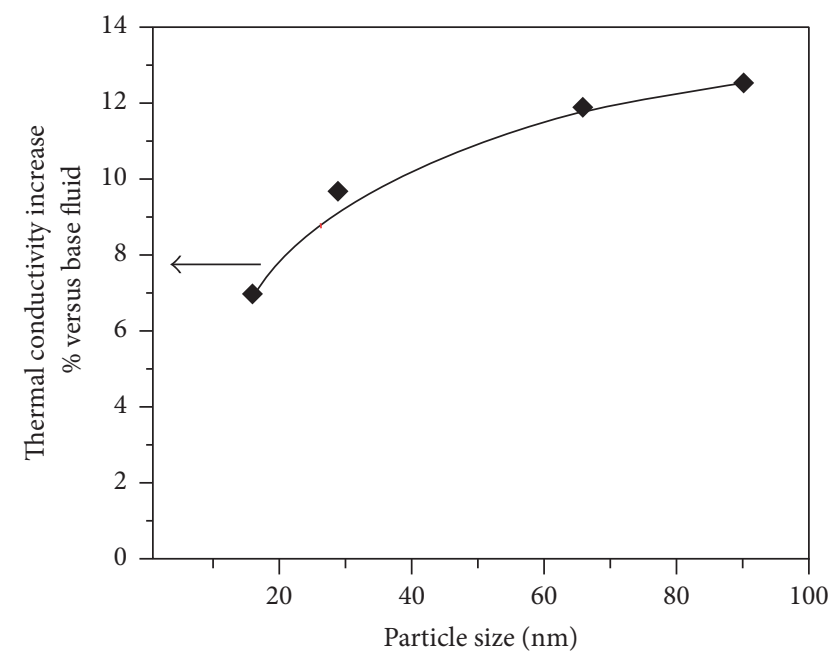

FIgUre 3: The effect of particle size of $\alpha$-SiC on the thermal conduction of water-based nanofluids $\left(22.5^{\circ} \mathrm{C}\right.$, concentration $\sim 4.1 \mathrm{vol} . \%$, and $\mathrm{pH}$ 9.4) [39].

the same rule has been confirmed by a large number of experimental results $[32,33]$.

At present, for the effect of particle size on the thermal conductivity of TFCs, inconsistent experimental results are arising. Xie et al. [31] studied the effect of alumina particles sizes (five different sizes of alumina particles $(\sim 12-302 \mathrm{~nm})$ ) on the thermal conductivity of nanofluids (ethylene glycol and pump oil). The results showed that the thermal conductivity of nanofluids decreased with increasing particles size (the thermal conductivity enhancement ratio of EG/aA25 (particle size: $60.4 \mathrm{~nm}$ ) compared to EG/aA-5 (particle size: $302 \mathrm{~nm}$ )) (Figure 1). Figure 2 showed the thermal conductivity of epoxy-silver nanoparticles composites with $80 \mathrm{~nm}$ was lower than that with $20 \mathrm{~nm}$ at the same filling fraction [34]. It suggested that the nanostructured networks played more important role than the size effect in the studied composites. However, other experimental results [3539] indicated that the thermal conductivity of nanofluids increased with increasing particles size (Figure 3) for many different particles.

For the inconsistent experimental phenomena, we propose the following explanation. The bigger particles show high intrinsic thermal conductivity and low solid/fluid interfacial thermal resistance, while the smaller particles show high dispersion in base fluid and strong coupling effect between particles and fluids and are easier to form heat conducting network. Therefore, the thermal conductivity of particles-based binary composites may show different trends for the particles size effect, which reflects the influence of the leading factors. Finally, the particles size effect on the thermal conductivity of nanofluids depends on the most important influence factors.

Furthermore, shape is another key influence factor for particles on the thermal conductivity of TFCs [4044]. Different $\mathrm{CuO}$ morphologies, namely, microspheres, nanoblocks, and microdisks, were filled in silicone with 9 vol.\% loading [42]. Compared to pure silicone, the thermal 
TABLE 1: Thermal conductivity of samples used in computations [44].

\begin{tabular}{lccc}
\hline $\begin{array}{l}\text { Polymer } \\
\text { matrix }\end{array}$ & $\begin{array}{c}\text { Thermal } \\
\text { conductivity } \\
(\mathrm{W} / \mathrm{m} \cdot \mathrm{K})\end{array}$ & Filler & $\begin{array}{c}\text { Thermal } \\
\text { conductivity } \\
(\mathrm{W} / \mathrm{m} \cdot \mathrm{K})\end{array}$ \\
\hline $\begin{array}{l}\text { Phenol } \\
\text { aldehyde }\end{array}$ & 0.111 & $\begin{array}{c}\text { Aluminum } \\
\text { oxide }\end{array}$ & 204 \\
\hline
\end{tabular}

conductivity enhancement of silicone-based thermal greases with different $\mathrm{CuO}$ shapes was 99\%, 139\%, and 116\%, respectively (Figure 4). The $\mathrm{CuO}$ microdisks with large aspect ratio could form thermal networks more effectively than the other two structures and showed higher thermal conductivity enhancement. ZnO particles with different shapes (tetrapodshaped, nanoparticles, and short column) were filled into silicone oil to form a nanofluid [43]. The experimental results demonstrated that the thermal greases with tetrapod-shaped $\mathrm{ZnO}$ showed the highest thermal conductivity compared to nanofluids with other shape fillers at the same volume fraction (Figure 5). The unique tetrapod-shaped $\mathrm{ZnO}$ was favorable to form thermal conductive networks and therefore greatly enhanced the heat conduction of composites.

Based on the law of the specific equivalent thermal conductivity and the law of minimal thermal resistance, Chauhan et al. [44] systematically investigated the effect of geometry of particles consisting of three different shapes, that is, spherical, hexagonal, and elliptical, on the effective thermal conductivity for polymer composites. At last, the equivalent thermal conductivity of composites was obtained for spherical, hexagonal, and elliptical fillers, respectively. Besides, the effect of shape for aluminum oxide on the thermal conductivity of phenol aldehyde/aluminum oxide composites (Table 1) was computed in Figure 6.

For spherical shape particles, the expression is

$$
k_{\mathrm{eff}}=\frac{1}{1 / k_{p}-\left(1 / k_{p}\right)\left(6 \phi_{f} / \pi\right)^{1 / 3}+2 /\left(k_{p}\left(4 \pi / 3 \phi_{f}\right)^{1 / 3}+\left(2 \phi_{f} / 9 \pi\right)^{1 / 3} \pi\left(k_{f}-k_{p}\right)\right)} .
$$

For hexagonal shape particles, the expression is

$$
k_{\mathrm{eff}}=\frac{1}{1 / k_{p}-\left(1.23 / k_{p}\right)\left(\phi_{f}\right)^{1 / 3}+2 /\left(1.62\left(k_{p} /\left(\phi_{f}\right)^{1 / 3}\right)+1.29\left(\phi_{f}\right)^{1 / 3}\left(k_{f}-k_{p}\right)\right)} .
$$

For elliptical shape particles, the expression is

$$
k_{\mathrm{eff}}=\frac{1}{1 / k_{p}-\left(1 / k_{p}\right)\left(6 \phi_{f} / \pi\right)^{1 / 3}+2 /\left(\left(k_{p} / \sqrt{2}\right)\left(\pi / 6 \phi_{f}\right)^{1 / 3}+\left(2 \phi_{f} / 9 \pi\right)^{1 / 3} \pi\left(k_{f}-k_{p}\right)\right)} .
$$

Here, $k_{\text {eff }}, k_{p}$, and $k_{f}$ are the effective thermal conductivity, the conductivity coefficients of the polymer matrix, and the filler particles, respectively. $\phi_{f}$ is the volume fraction of filler in the resin matrix.

2.2. 1D Nanowires (Nanorods and Nanotubes). Equilibrium and nonequilibrium molecular dynamics simulations predicted that carbon nanotubes (CNTs) showed very high intrinsic thermal conductivity value [45]. Meanwhile, experimental measurements also confirmed that the intrinsic thermal conductivity of single-walled carbon nanotube achieved $2400 \mathrm{~W} / \mathrm{m} \cdot \mathrm{K}$. Besides it depended strongly on the numbers of wall and aspect ratios [46-48]. As a result, CNTs attracted considerable interest as filler in matrix for thermal conductivity enhancement. Certainly, the thermal property of composites should be affected by the structure and length of
CNTs. Five different structures, namely, single-walled CNTs, double-walled CNTs, few-walled CNTs, and two different multiwalls, were applied in water-based nanofluids. The experimental results confirmed that the thermal conductivity of nanofluids decreased with the increasing layer number of nanotube walls [49], which could be attributed to the liquid-solid interface. CNTs with different aspect ratios were obtained by sonication-induced scission treatment, that is, averaging 50 (short CNTs) and 500 (long CNTs). These tubes were used as filler (up to $1.0 \mathrm{wt} \%$ ) in carbon nanotube/epoxy nanocomposite. The thermal conductivity of nanocomposites showed a modest increase with the increase of aspect ratio [50].

Compared with particles, nanowires show large surface area, high aspect ratio, and long phonon mean free paths, which help in the thermal conductivity enhancement of 


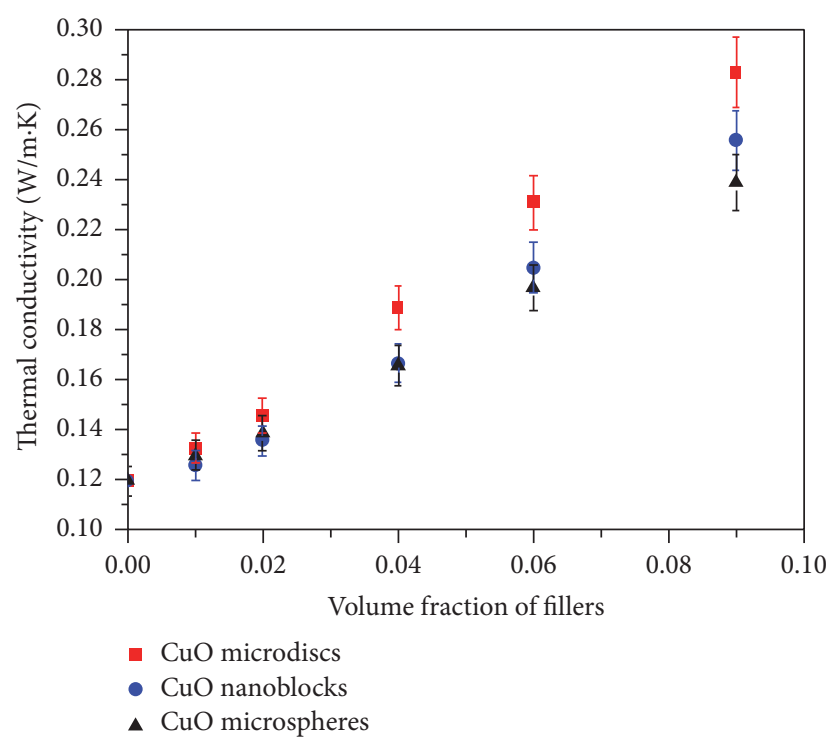

FIGURE 4: Thermal conductivity of silicone-based thermal grease as a function of loading for different $\mathrm{CuO}$ shapes [42].

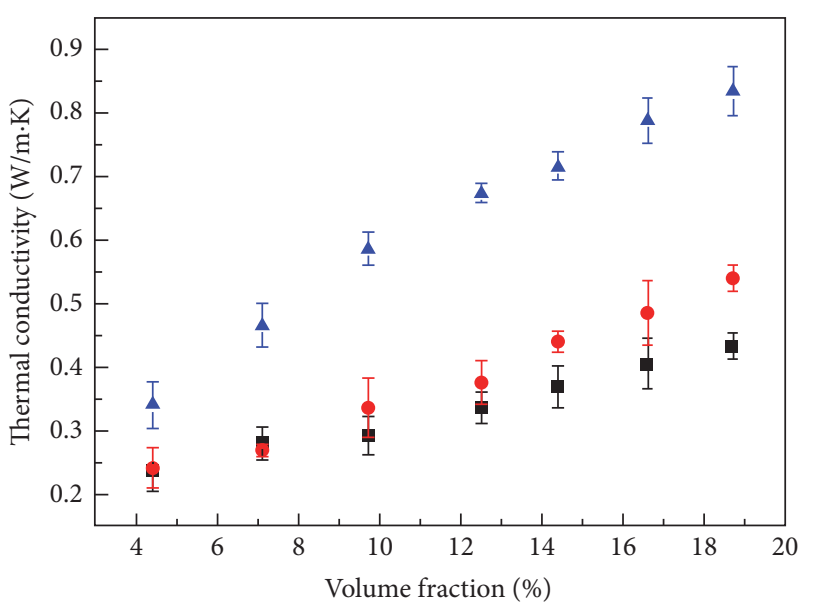
- ZnO-NPs
- $\mathrm{ZnO}-\mathrm{SC}$
- $\mathrm{T}-\mathrm{ZnO}$

Figure 5: Thermal conductivity of composite as a function of volume fraction for different shape $\mathrm{ZnO}$ fillers [43].

TFCs [51-54]. Furthermore, nanowires are easy to form end to end thermal conductive network in the matrix due to their high aspect ratios [55]. Pal et al. have studied three different shapes of $\mathrm{CuO}$ nanospheres $(5-10 \mathrm{~nm}$, surface area: $\left.41 \mathrm{~m}^{2} \mathrm{~g}^{-1}\right)$, nanorods $(L \times W=100-140 \mathrm{~nm} \times 30-40 \mathrm{~nm}$, surface area: $\left.53 \mathrm{~m}^{2} \mathrm{~g}^{-1}\right)$, and nanowires $(200-210 \mathrm{~nm} \times 2-5 \mathrm{~nm}$, surface area: $61 \mathrm{~m}^{2} \mathrm{~g}^{-1}$ ) on the thermal conductivity of suspensions containing water and ethylene glycol base fluids. It was found that the suspensions with $\mathrm{CuO}$ nanorods and nanowires always displayed higher thermal conductivity than those with $\mathrm{CuO}$ nanospheres [56]. The thermal conductivity of ethylene glycol suspensions containing three different shapes of SiC-sphere $(25 \mathrm{~nm}), \mathrm{SiC}$-cylinder $(600 \mathrm{~nm})$, and

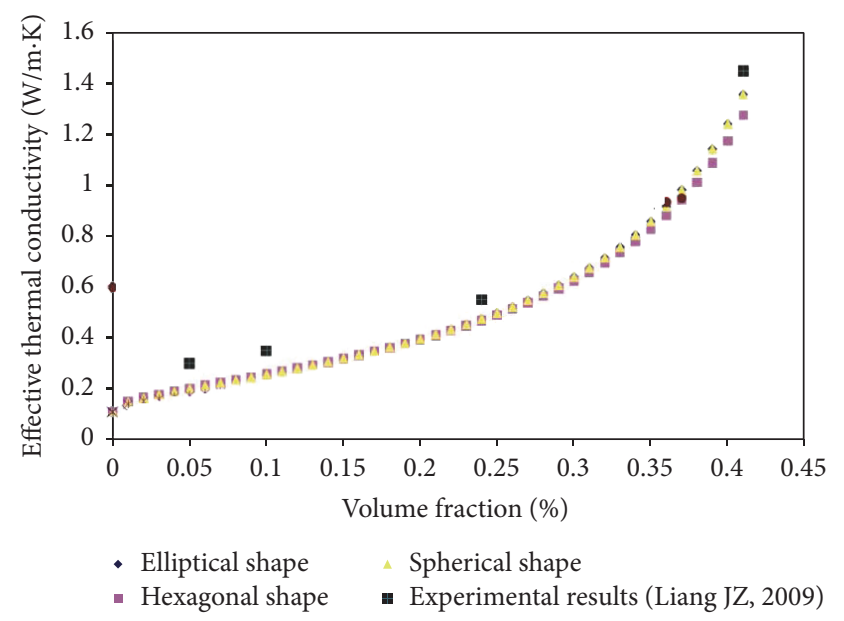

FIgURE 6: Thermal conductivity of phenol aldehyde/aluminum oxide composite as a function of volume fraction for different shape [44].

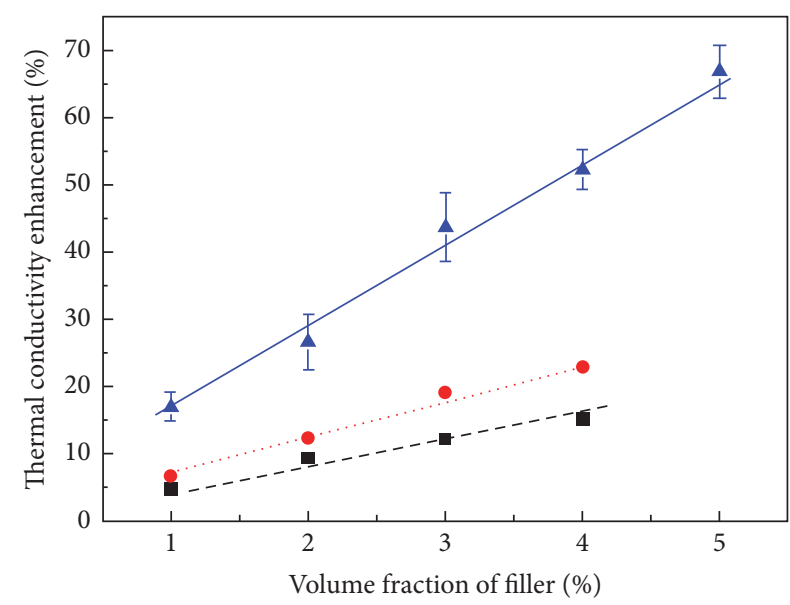

- SiC-sphere (reference [31]) - - - H\&C model: sphere

- SiC-cylinder (reference [31]) ..... H\&C model: cylinder

- SiC-nanowire

— H\&C model: nanowire

FIGURE 7: Comparison of thermal conductivity enhancements of different nanofluids consisting of the experimental results and calculated values from the Hamilton-Crosser model [30, 31].

SiC-nanowire $(6 \mu \mathrm{m})$ was synthetically investigated in [30, 31]. The measured experimental data was shown in Figure 7, and it demonstrated that the suspensions containing SiCnanowire have the highest thermal conductivity.

Shape factor is one of the most important factors affecting the thermal conductivity of nanowires-based nanocomposites. Fang et al. have studied the size effects of Ag nanowires on the thermal conductivity of ethylene glycol-based nanofluids. This result exhibited a linear relationship between the relative enhancement in thermal conductivity and the specific surface area of Ag nanowires except a percolation-like nonmonotonous behavior appearing at $1 \mathrm{mg} / \mathrm{mL}$ [57]. The thermal conductivity of three water-based suspensions consisting of high aspect ratio fillers, copper nanowires, silver nanowires, and carbon nanotubes, was measured. Compared to 


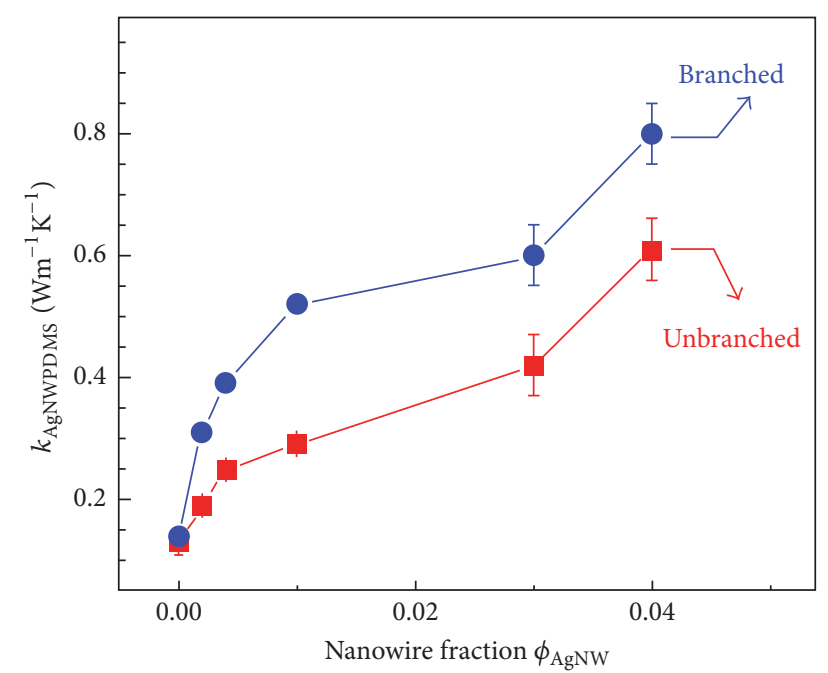

Figure 8: Thermal conductivity of Ag nanowires/polydimethylsiloxane nanocomposites with branched and unbranched Ag nanowires as a function of loading [58].

nanofluids with copper nanowires and carbon nanotubes, silver nanowires-based nanofluids showed the highest thermal conductivity, and this revealed that filler with higher thermal conductivity was not the only decisive factor for improving the thermal transport properties of nanofluids [53]. In addition, the experimental results demonstrated that the thermal conductivity of composites from Ag nanowires with unique branching structure as additive in polydimethylsiloxane yielded up to $60 \%$ higher than that consisting of unbranched Ag nanowires filler at low fractions (Figure 8) [58].

2.3. 2D Nanosheets (Nanoplatelets). Nanosheets consist of single-layer or fewer-layers atoms, possessing high specific surface area, and are easy to form strong coupling interaction with matrix. The typical 2D materials contain graphene, graphene oxide, and boron nitride nanosheets. Experimental results were consistent with theoretical prediction value, and it was confirmed that graphene showed extremely high intrinsic thermal conductivity. Meanwhile, boron nitride nanosheets also showed relatively high intrinsic thermal conductivity. It was exciting that 2D boron nitride was electrical insulation, and it was also called "white graphene." Theoretical thermal conductivity of graphene was up to $8000-10000 \mathrm{~W} / \mathrm{m} \cdot \mathrm{K}$ at room temperature by molecular dynamics simulation. In addition, it will be severely affected by the size $[59,60]$. The intrinsic thermal conductivity value of suspended single-layer graphene was measured at room temperature by Raman spectroscopy and it is in the range $\sim(4.84 \pm 0.44) \times 10^{3}$ to $(5.30 \pm 0.48) \times 10^{3} \mathrm{~W} / \mathrm{m} \cdot \mathrm{K}[61-64]$. Therefore, nanosheets as the thermal conductive additive in TFCs for thermal conductivity enhancement were one of the hot research fields.

There are many reports about nanosheets as filler for improving the thermal conductivity of TFCs [65-73]. To the best of our knowledge, Yu et al. first reported the thermal conductivity of ethylene glycol-based nanofluids with

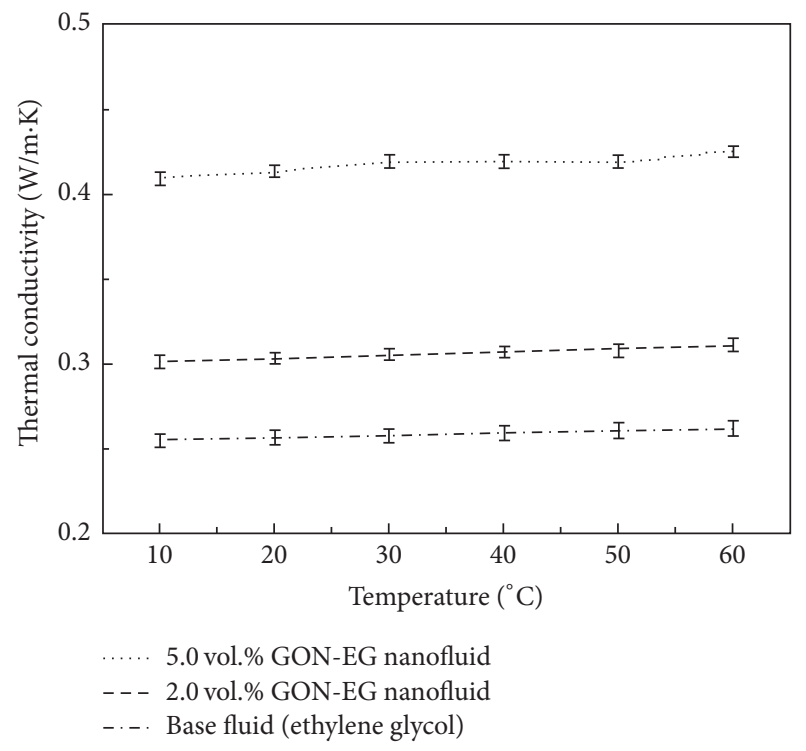

FIgURE 9: Thermal conductivity of nanofluids with the change of temperatures [65].

graphene oxide sheets filler [65]. The thermal conductivity enhancement increased with the increasing volume fraction of graphene oxide nanosheets. The enhancement ratio was up to $61.0 \%$ with the graphene oxide loading of 5.0 vol.\% (Figure 9). Moreover, the enhancement ratio was constant with the change of temperature. The mixture of graphene and multilayer graphene was utilized to improve the thermal properties of polymer [74]. An enhancement of thermal conductivity by $2300 \%$ with the filler of 10 vol. $\%$ loading fraction was found. It is higher than anything reported to date. For commercial thermal grease, the thermal conductivity was increased from an initial value of $5.8 \mathrm{~W} / \mathrm{m} \cdot \mathrm{K}$ to $14 \mathrm{~W} / \mathrm{m} \cdot \mathrm{K}$ with the filler of $2 \%$ loading (Figure 10).

Many other reports indicate that the thermal conductivity of nanosheets-based nanocomposites will be severely affected by the filler geometric dimension $[75,76]$. Chen et al. [77] developed an analytical model for simultaneously calculating the effects of geometric dimension on the thermal conductivity of polymer composites containing hexagonal boron nitride (h-BN). Setting the h-BN aspect ratio to a constant value of 10 , both the in-plane thermal conductivity and through-plane thermal conductivity of the composites increased as the h-BN diameter increased when it was lower than $5 \mu \mathrm{m}$. However, the further improvement of composite thermal conductivity became insignificant when it was higher than $5 \mu \mathrm{m}$. Keeping the filler diameter at a fixed value, both the in-plane thermal conductivity and through-plane thermal conductivity of the composites increased continuously as the filler aspect ratio increased. Yu et al. [78] used different thickness of graphite nanoplatelets as filler for epoxy composites. It was found that the epoxy composites with a thickness of $2 \mathrm{~nm}$ filler (loading of 5 vol.\%) achieved a thermal conductivity of $6.44 \mathrm{~W} / \mathrm{m} \cdot \mathrm{K}$, and the thermal conductivity enhancement was increased by more than $3000 \%$. 


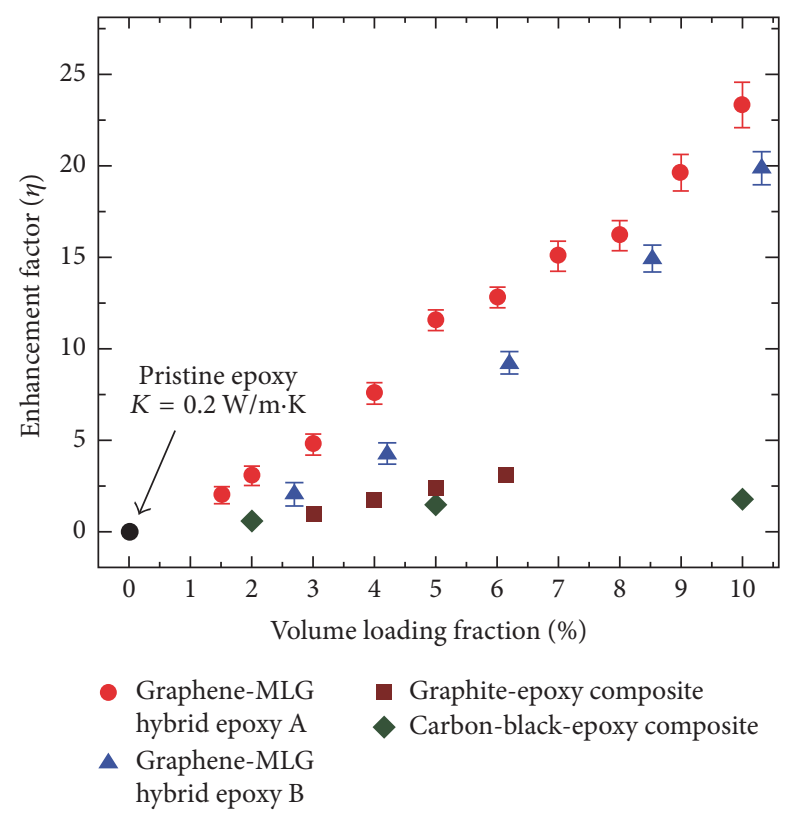

FIGURE 10: Thermal conductivity enhancement in the graphene and multilayer graphene epoxy nanocomposite as a function of the filler volume loading [74].

\section{Heat Transfer Enhancement Based on Synergistic Effect}

Synergistic effect means that different fillers with complementary shapes and high thermal conductivity are easy to form efficient thermal conductive networks, which lead to enhancing thermal property of composites. For synergistic effect, the key issue is how to fabricate fillers with complementary shapes and construct three-dimensional network.

3.1. The Synergistic Effect of $1 D$ Nanomaterials and $O D$ Nanomaterials. Hybrid size particles filler can improve the thermal conductivity of the TFCs [79-82]. As can be seen from Figure 11, the small particles can easily occupy the space between the adjacent large particles, which leads to larger packing density of the filler in the matrix and lower thermal resistance among adjacent conductive filler [83]. Due to the high thermal conductivity and large aspect ratio, CNT attracted great attention as hybrid filler with particles for thermal conductivity enhancement of TFCs. Such as CNT was added as a synergizer in alumina sphere/thermoplastic polyurethane mixture [84], it was found that the thermal conductivity of mixture was enhanced 2- to 3-fold when the mass ratio (Al-CNT hybrid:mixture) was $1: 20$. The enhancement value was higher than that by individual CNT; this was because the hybridized Al-CNT could improve the compatibility between the filler and the matrix and could reduce the modulus mismatch at the interface. Jiao et al. investigated the synergistic effects of multiwalled carbon nanotubes and aluminum nitride particles on the thermal conductivity of epoxy composites [85]. Results showed that the 1D MWCNTs with superb thermal conductivity and large aspect ratio easily bridged the isolated AlN particles to

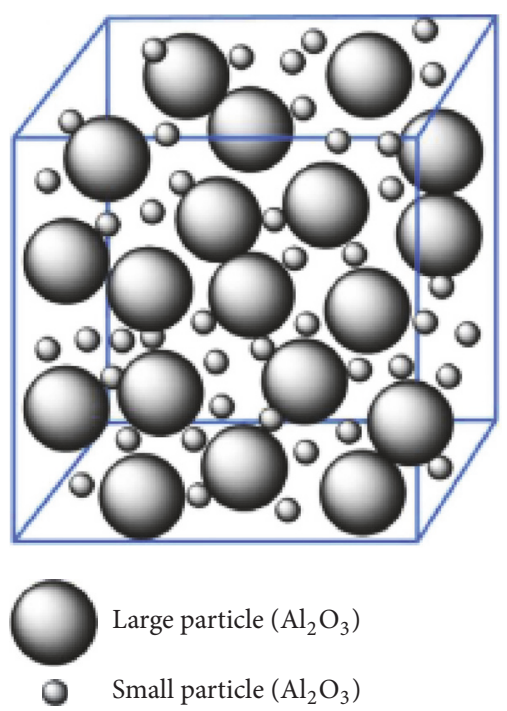

FIgURE 11: Schematic for the distribution of hybrid size alumina particles [83].

form thermal conductive network, which provided effective and fast pathway for phonon transport in the composites. Chen et al. studied the synergistic effects of Ag/MWNT composites on the thermal conductivity of the water-based nanofluids [86]. The measurement results showed that the thermal conductivity of the water-based nanofluids containing $\mathrm{Ag} / \mathrm{MWNT}$ composites was higher than that of those containing pristine or functionalized MWNTs (Figure 12). $\mathrm{Cu} / \mathrm{MWCNTs}$-based nanofluids have been synthesized in this work [87]. Results showed that the thermal conductivity of $\mathrm{Cu}$ /MWCNTs-based nanofluids composites was higher than that of MWCNTs based nanofluids composites (Figure 13).

3.2. The Synergistic Effect of $2 D$ Nanomaterials and $0 D$ Nanomaterials. Graphene is a typical 2D nanomaterial, with extremely high intrinsic thermal conductivity and large specific surface area. As a result, it becomes an excellent additive in TFCs for thermal conductivity enhancement, but there is a practical problem that graphene is very easy to stack in fabrication process, decreasing the thermal conductivity. Therefore, how to make the filler disperse in the matrix is still a challenge. Qian et al. have successfully fabricated alumina-coated graphene sheet hybrids by an electrostatic self-assembly method. The alumina-coated graphene was incorporated into polyvinylidene fluoride matrix and obtained corresponding composites [88]. The alumina-coated graphene sheet hybrid with unique structure combined the advantages of both graphene and $\mathrm{Al}_{2} \mathrm{O}_{3}$. Experimental result showed that the thermal conductivity of the composites with $40 \mathrm{wt} \%$ filler was up to $0.586 \mathrm{~W} / \mathrm{m} \cdot \mathrm{K}$ (Figure 14). Yu et al. used alumina and graphene sheets as hybrid filler in poly(ethylene-co-vinyl acetate) and built a strong three-dimensional network of heat conducting path in matrix [89]. This unique structure effectively prevented the interlayer restacking of graphene sheets and reduced the thermal contact resistance between fillers and interface. 


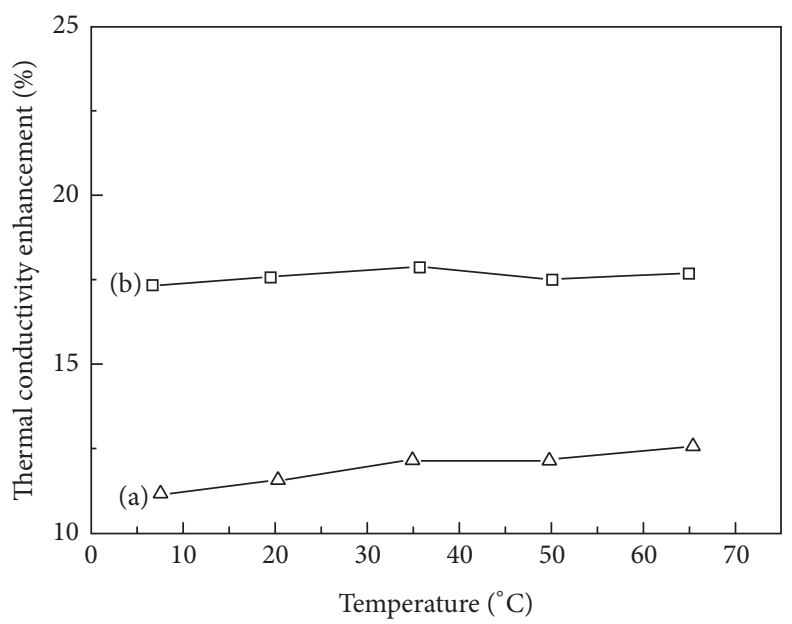

FIGURE 12: Thermal conductivity enhancement of nanofluids filled with (a) functionalized MWNTs and (b) Ag/MWNT composites. The volume fraction filler is $1.0 \%$ [86].

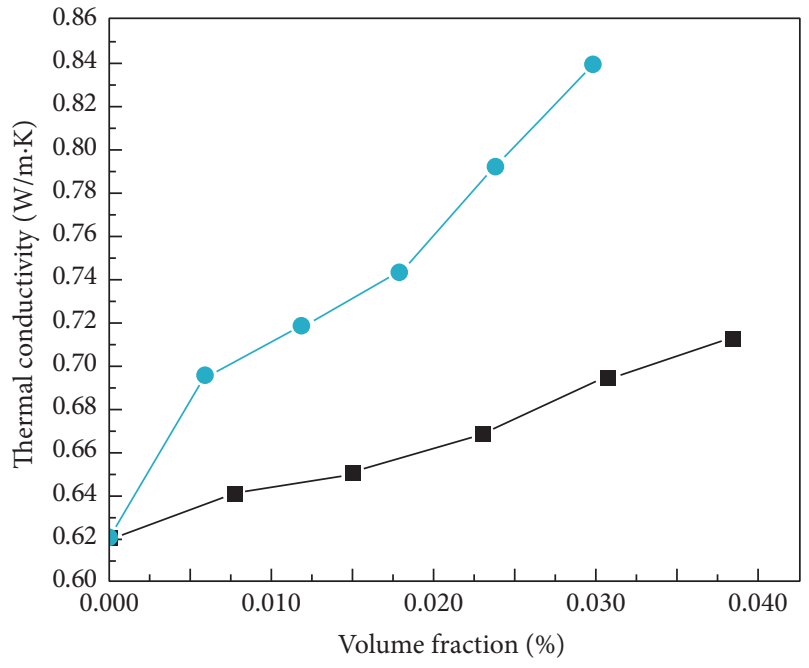

Base fluid-DI water

- - MWCNTs

- $\mathrm{Cu} / \mathrm{MWCNTs}$

(a)

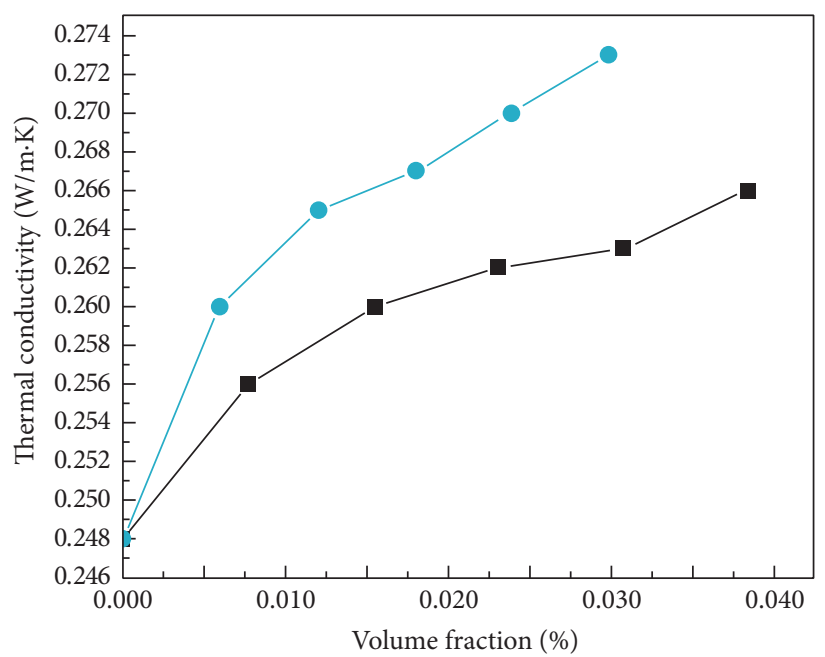

Base fluid-EG

- MWCNTs

- $\mathrm{Cu}$ /MWCNTs

(b)

FIGURE 13: The relation between thermal conductivity and the volume fraction of MWCNT and Cu/MWCNTs in base fluid (a) deionized water and (b) ethylene glycol [87].

The measurement results showed high thermal conductivity up to $2.40 \pm 0.07 \mathrm{~W} / \mathrm{m} \cdot \mathrm{K}$, much higher than that with single filler at the same loading (Figure 15). Additionally, a three-dimensional schematic model for strong synergistic effect was supplied in this work (Figure 16). Chen et al. have successfully fabricated epoxy resin-based TIMs with Ag nanoparticle-decorated graphene nanosheets fillers [90]. The result demonstrated that the thermal conductivity of TIMs significantly improved (Figure 17) due to the extremely high intrinsic thermal conductivity of graphene and the unique thermal conductive networks formed by Ag nanoparticles acting as "spacers" intercalated the distance between the graphene sheets. Goyal and Balandin used small graphene loading fraction to improve the thermal properties of $\mathrm{Ag} /$ epoxy composites [8]. The results showed that the thermal conductivity of composites was increased by $\sim 500 \%$ in the temperature range from $300 \mathrm{~K}$ to $400 \mathrm{~K}$ with graphene loading fraction of $5 \mathrm{vol} . \%$ (Figure 18). This improvement can be attributed to the high intrinsic thermal conductivity of graphene, strong coupling between graphene and matrix, and the wide range of the length-scale of fillers.

Boron nitride nanosheets (BNNSs) are another example of typical 2D nanomaterials. Certainly, BNNS is also an excellent additive in TFCs for thermal conductivity 


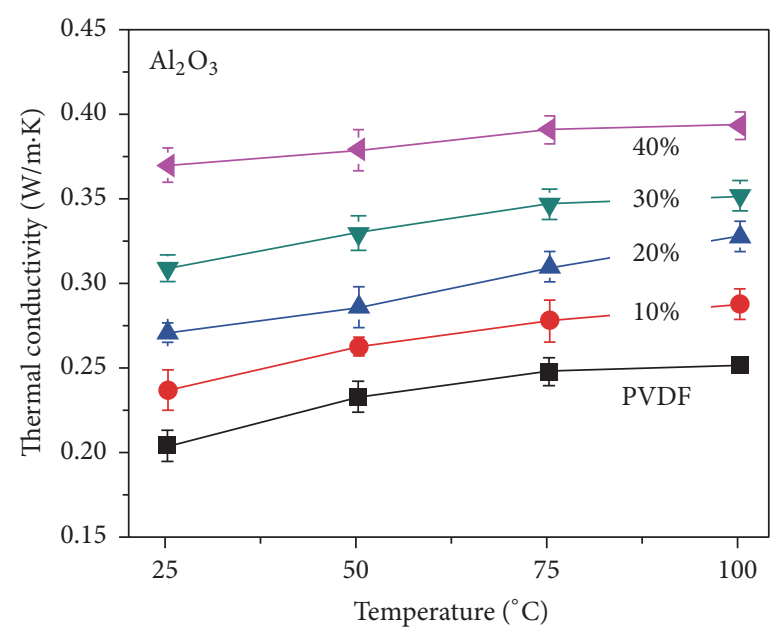

(a)

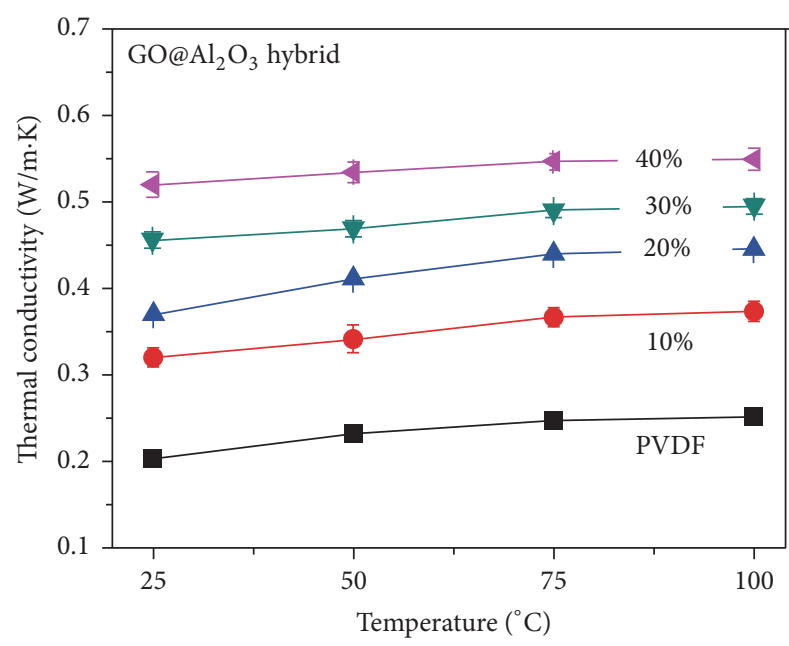

(c)

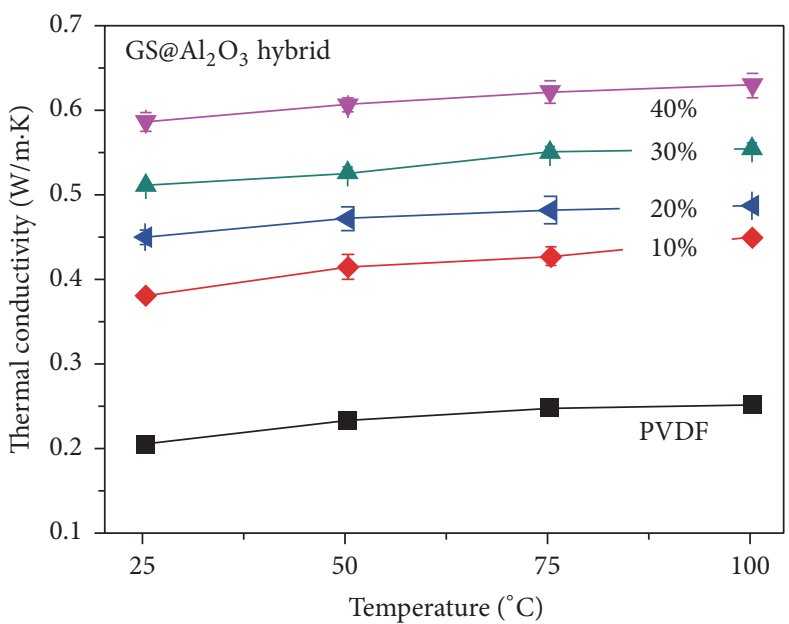

(b)

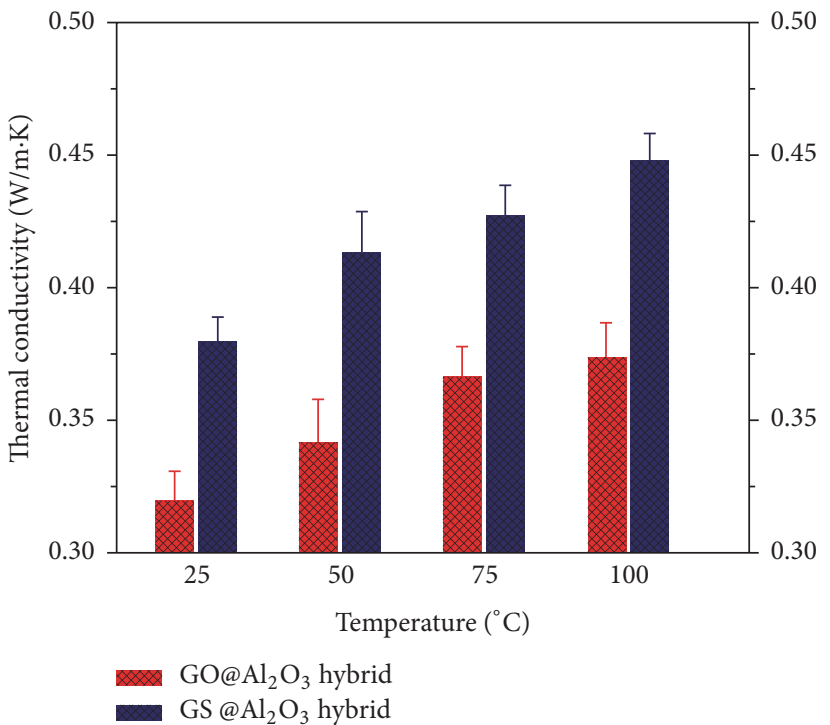

(d)

FIGURE 14: The effect of temperature on the thermal conductivity of the composites filled with (a) $\mathrm{Al}_{2} \mathrm{O}_{3},(\mathrm{~b}) \mathrm{GS}_{\mathrm{Al}} \mathrm{Al}_{2} \mathrm{O}_{3}$ hybrid (GS : $\mathrm{Al}_{2} \mathrm{O}_{3}$ =1:20), and (c) $\mathrm{GO} @ \mathrm{Al}_{2} \mathrm{O}_{3}$ hybrid $\left(\mathrm{GO}: \mathrm{Al}_{2} \mathrm{O}_{3}=1: 20\right)$ at different filler mass fraction. (d) Comparison of thermal conductivity between PVDF/GO@ $\mathrm{Al}_{2} \mathrm{O}_{3}$ and PVDF/GS@ $\mathrm{Al}_{2} \mathrm{O}_{3}$ at the mass fraction of $10 \mathrm{wt} \%$. GS: graphene; GO: graphene oxide; PVDF: polyvinylidene fluoride [88].

enhancement and it faces the same dispersion uniformity problem in matrix. For enhancing the thermal conductivity of polymer, silver nanoparticle-deposited boron nitride nanosheets were filled in polymer [91], owing to the bridging three-dimensional thermal conductive network between silver nanoparticles and boron nitride nanosheets. The thermal conductivity of the composite filled with the silver nanoparticle-deposited boron nitride nanosheets was up to $3.06 \mathrm{~W} / \mathrm{m} \cdot \mathrm{K}$, while that filled with single-boron nitride nanosheets was $1.63 \mathrm{~W} / \mathrm{m} \cdot \mathrm{K}$ at the boron nitride nanosheets loading of 25.1 vol.\%. Fitting the measured thermal conductivity of epoxy composite by physical model exhibits that the composite filled with silver nanoparticle-deposited boron nitride nanosheets outperforms the one filled with singleboron nitride nanosheets, which can be attributed to the lower thermal contact resistance at the interfaces between boron nitride nanosheets and matrix.

3.3. The Synergistic Effect of 2D Nanomaterials and $1 D$ Nanomaterials. Due to the special structure of a complementary relationship between $2 \mathrm{D}$ nanomaterials and $1 \mathrm{D}$ nanomaterials, 1D nanomaterials can bridge 2D nanosheets and form an efficient three-dimensional thermal conductive network in matrix, which supplies a fast transport channel for phonon [92-95]. A synergistic enhancement effect in the thermal conductivity of epoxy composites was achieved by combining SWNT and graphitic nanoplatelet fillers (Figure 19) [96]. It explained that this synergism originated from the bridged network between planar nanoplatelets and flexible SWNTs which lead to a reduced thermal interface resistance along 


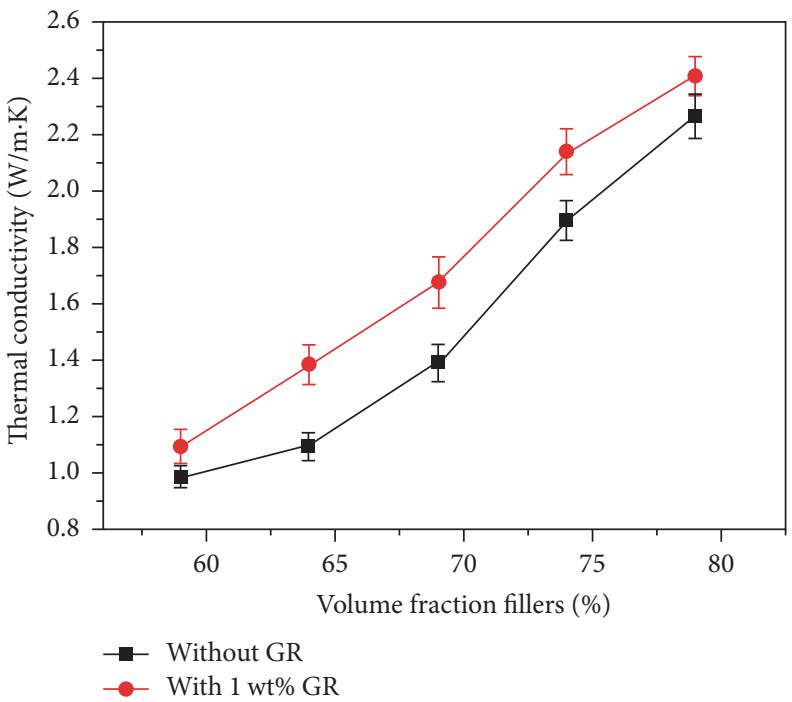

FIGURE 15: Thermal conductivity comparison of alumina/poly(ethylene-co-vinyl acetate) composites with graphene and without graphene [89].

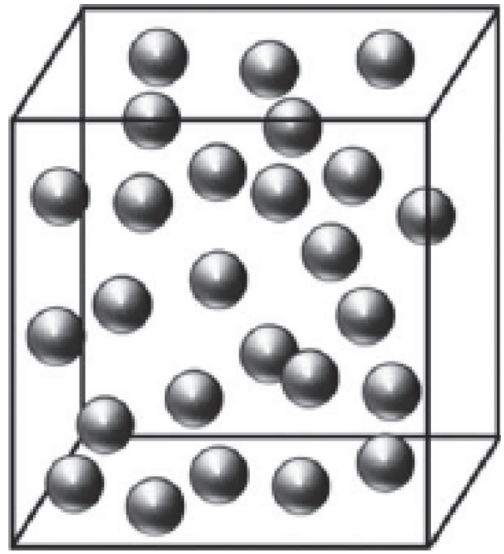

Large particle $\left(\mathrm{Al}_{2} \mathrm{O}_{3}\right)$

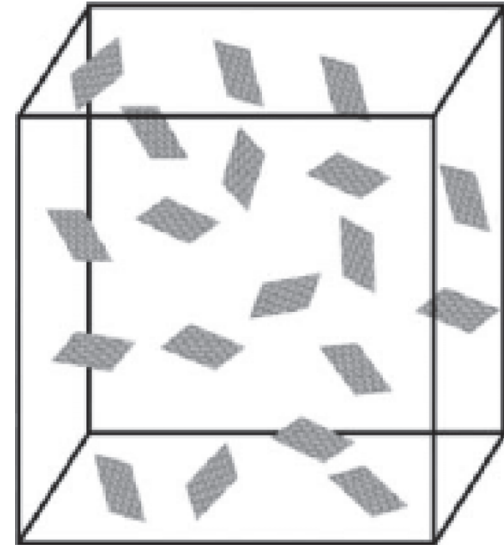

Graphene sheet

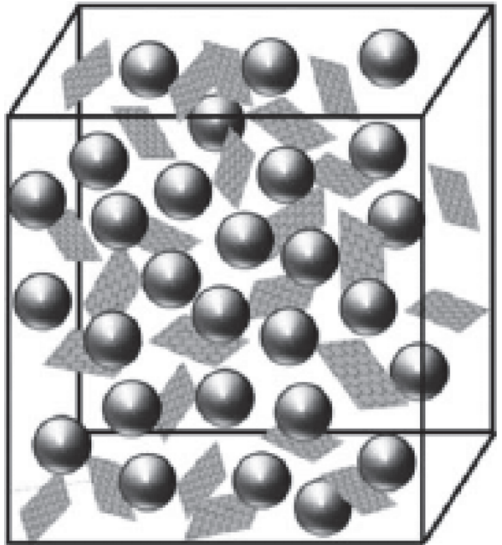

Large particle $\left(\mathrm{Al}_{2} \mathrm{O}_{3}\right)$

Graphene sheet

(c)

FIGURE 16: Schematics of the three-dimensional thermal conductive network formation for (a) $\mathrm{Al}_{2} \mathrm{O}_{3}$ particles, (b) graphene sheet, and (c) hybrid filler of $\mathrm{Al}_{2} \mathrm{O}_{3}$ /graphene in poly(ethylene-co-vinyl acetate) [89].

the hybrid filler network because of the extended contact area of the SWNT-GNP (Figure 20). Thermal conductivity enhancement of deionized water-based nanofluids filled with graphene and graphene-MWNT at room temperature for $0.04 \%$ volume fraction was $9.2 \%$ and $10.5 \%$, respectively [92]. Thermal conductivity of the water-based nanofluids was improved with hybrid graphene-MWNT as additives, which could be owing to prevention of restacking of graphene sheets by MWNT as well as synergistic effect between graphene and MWNT. Graphene oxide-MWCNT/epoxy composites were prepared by epoxy wetting [97]. Results showed that the thermal conductivity of composites was increased due to the formation of efficient three-dimensional heat conduction paths by the addition of MWCNTs.

A novel strategy was designed to enhance thermal conductivity of epoxy composites by filling hybrid 2D boron nitride nanosheets (BNNSs) and 1D boron nitride nanotubes (BNNTs) [98]. The thermal conductivity of epoxy composites with 1-pyrenebutyric acid functionalized BNNTs/BNNSs hybrid fillers was up to $0.47 \mathrm{~W} / \mathrm{m} \cdot \mathrm{K}$ at $2 \mathrm{wt} \%$ filler loading, higher than that with individual 1-pyrenebutyric acid functionalized BNNTs or BNNSs fillers (Figure 21). This is because 1-pyrenebutyric acid functionalized BNNTs/BNNSs nanocomposites have good dispersion and high compatibility with 


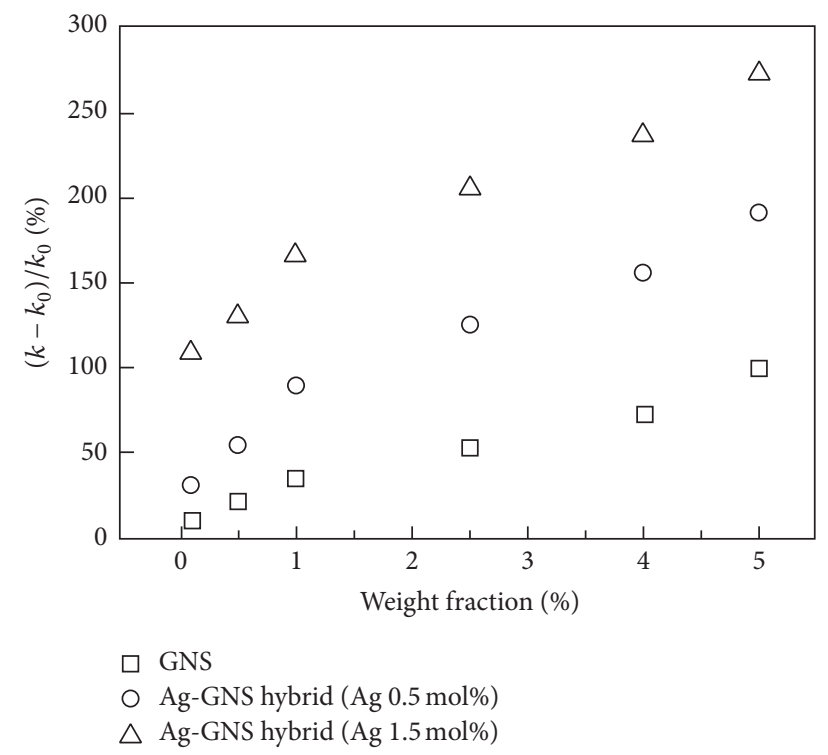

FIGURE 17: Thermal conductivity enhancement of epoxy resin composite with different weight fraction of Ag-GNS hybrid fillers $\left(20^{\circ} \mathrm{C}\right)[90]$.

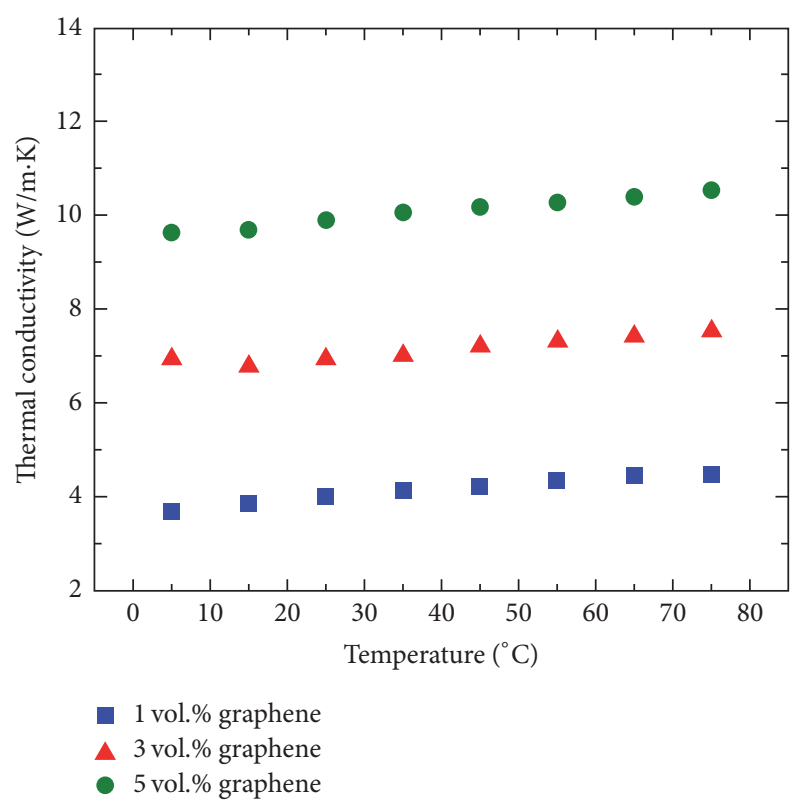

FIGURE 18: The effect of temperature on the thermal conductivity of the hybrid graphene-silver-epoxy composite with different volume fraction of filler loading, $1 \%, 3 \%$, and $5 \%$, respectively [8].

epoxy matrix (Figure 22). Yan et al. demonstrated an effective method for improving the thermal properties of the epoxy composites by incorporation of hybrid BNNTs-BNNSs nanofillers [99]. The nanofillers BNNTs-BNNSs showed homogeneous dispersion in matrix and a strong interface interaction, resulting in a large enhancement for thermal conductivity, with a $95 \%$ enhancement in thermal conductivity by addition of only 1 vol.\% loading. Furthermore, the theoretical analysis indicated that an exceptional thermal

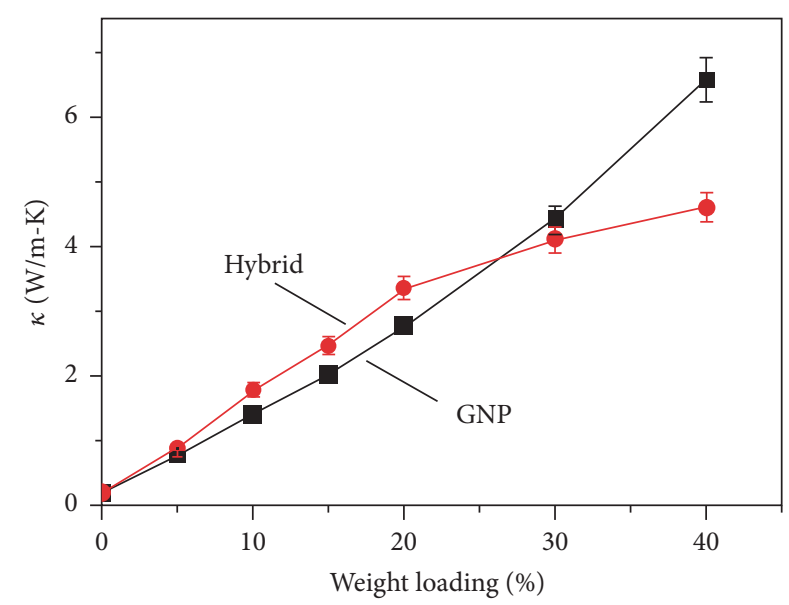

FIGURE 19: Thermal conductivity of GNP/epoxy composites (black squares) and GNP-SWNT/epoxy composites (red circles, GNP : SWN $=3: 1$ ) as a function of the filler loading [96].

conductivity enhancement can be achieved by adding only a small amount of BNNTs in the hybrid system. The theoretical results were in good agreement with experimental data reported in the previous literature and well described the thermal conductivity behavior of composites with hybrid fillers. The mathematic model is given by

$$
\begin{aligned}
& \frac{K^{*}}{K_{m}} \\
& =\frac{1+f_{t}\left(K_{t}^{\mathrm{eff}} / K_{m}\right) / 3+2\left(f_{s}-0.001\right)^{a}\left(K_{s}^{\mathrm{eff}} / K_{m}\right) / 3}{1-\left(2 f_{t}+f_{s}\right) / 3}, \\
& K_{t}^{\mathrm{eff}}=\frac{K_{t}}{2 R_{K} K_{t} / l_{t}+1}, \\
& K_{s}^{\mathrm{eff}}=\frac{K_{s}}{2 R_{K} K_{s} / l_{s}+1},
\end{aligned}
$$

where $K$ is the thermal conductivity; $f$ is filler volume fraction; $R_{K}$ is interfacial thermal resistance; $l_{s}$ is the width of the BNNT and BNNS; $l_{t}$ is the length of the BNNT and BNNS; subscripts $t, s$, and $m$ and superscript eff represent BNNT, BNNS, and epoxy and effective thermal conductivity, respectively.

\section{Conclusion and Outlook}

The filler shape is one of the most important but easily overlooked factors for the thermal conductivity enhancement of TFCs. In this article, from theoretical and experimental results, we provide a systematic review of the effect of filler shape on the thermal conductivity of TFCs. It mainly includes $0 \mathrm{D}$ particles, $1 \mathrm{D}$ nanotubes, $2 \mathrm{D}$ nanosheets, and the formation of complementary structure between different kinds of shapes. The fillers with unique shape are easy to form thermal conductivity network, resulting in higher thermal conductivity. Undoubtedly, high thermal conductivity for TFCs is still one of the biggest challenges, thus suggesting possible 


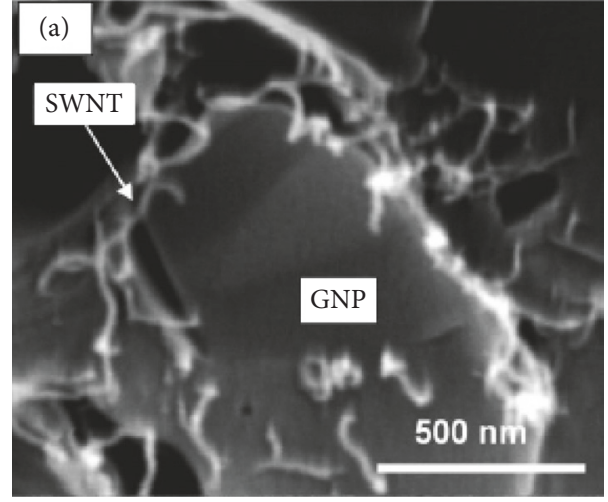

(a)

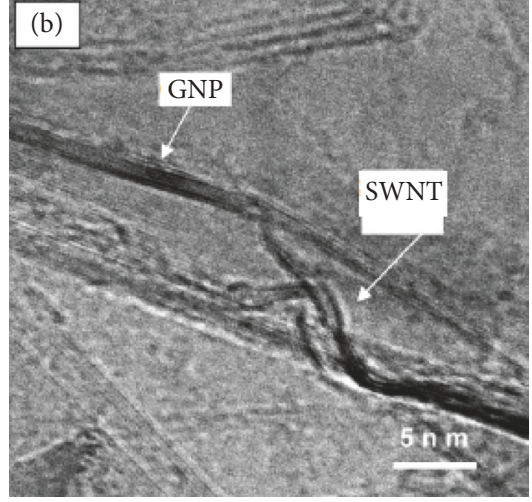

(b)

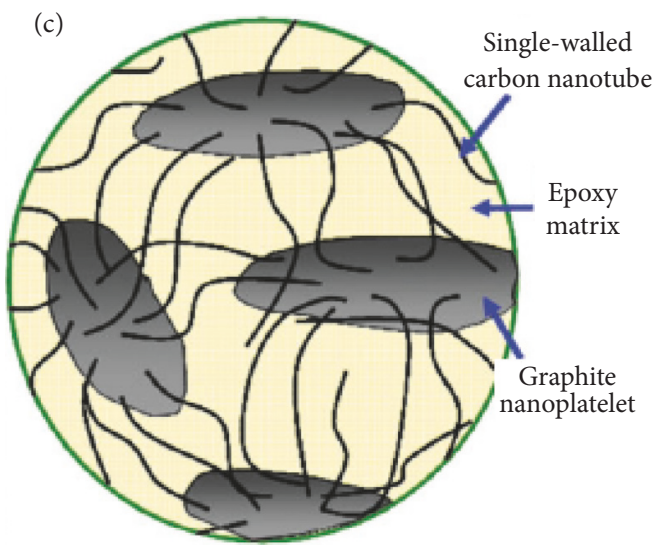

(c)

FIGURE 20: (a) SEM and (b) TEM images of SWNTs bridged adjacent graphite nanoplatelets in GNP-SWNT hybrid filler/epoxy composite. (c) Schematic representation of GNP-SWNT thermal conductive network in polymer matrix [96].

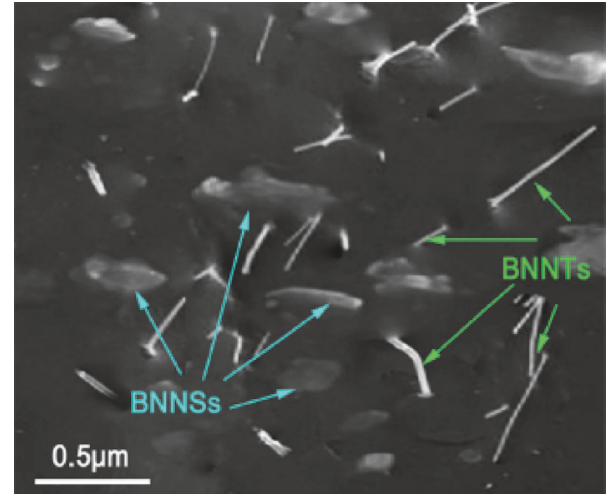

FIGURE 21: SEM image of the cross section of 1-pyrenebutyric acid-(BNNT + BNNS)/epoxy composites [98].

way of further improving thermal properties for TFCs as follows:

(1) How to prepare the designed low-dimensional materials with large aspect ratio? It will depend on the development of nanomaterial preparation technics and the parameters of preparation process. The fillers with large aspect ratio easily form efficient end to end three-dimensional thermal conductive network in matrix.

(2) How to disperse the low-dimensional materials into the matrix? To reduce the interface thermal resistance is one of the important issues. Surface modification could be a good way, but it always reduces the intrinsic thermal conductivity of the low-dimensional materials. More effective methods to obtain the homogeneous composite need to be developed.

(3) How to get the TFCs with high thermal conductivity but electrical insulation? Now the fillers with high thermal conductivity consist of carbon nanotubes, graphene, and metal. But they possess high electron mobility. BN, AlN, SiC, and so on with high thermal conductivity but electrical insulation represent a new development direction.

(4) How to build a new heat conduction network? It is formed by chemical bonding but physical contact. The chemical bonding heat conduction network reduces the thermal resistance at the interface between additives. 


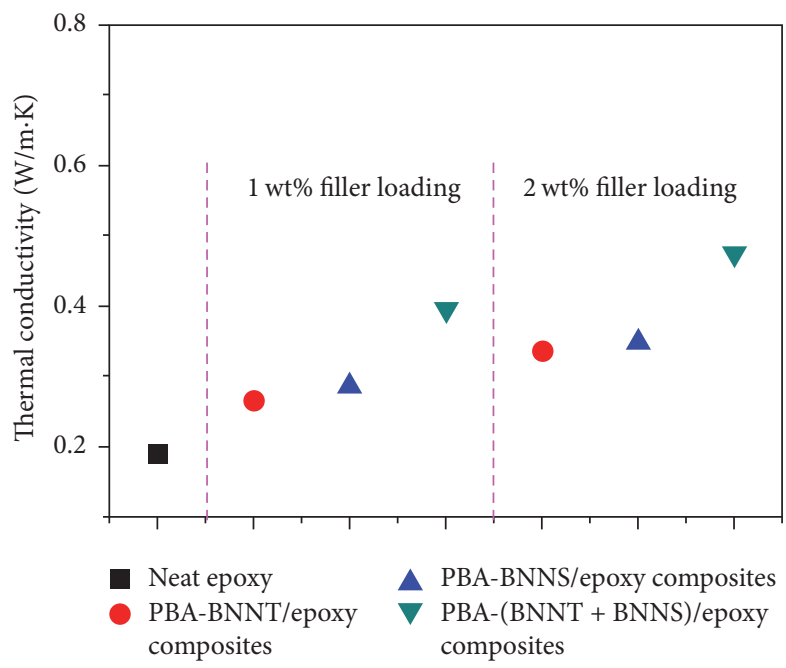

(a)

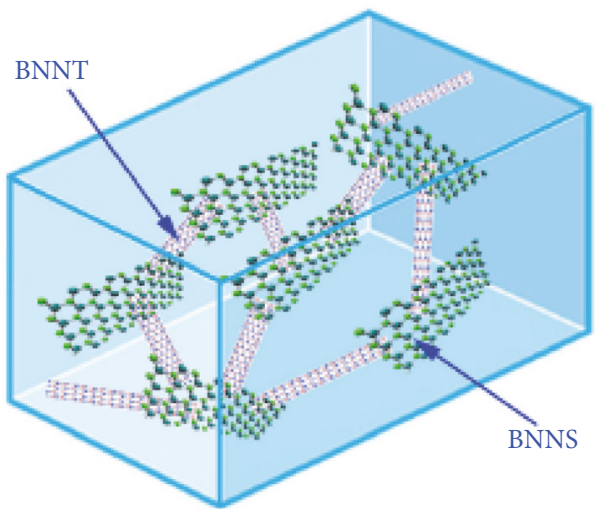

(b)

Figure 22: (a) Thermal conductivity of neat epoxy, PBA-BNNT/epoxy, PBA-BNNS/epoxy, and PBA-(BNNT + BNNS)/epoxy composites with filler loading of 1 and $2 \mathrm{wt} \%$. (b) Schematic diagram of BNNT/BNNS thermal conductive network formation in epoxy matrix [98]. PBA: 1-pyrenebutyric acid.

\section{Conflicts of Interest}

The authors declare that there are no conflicts of interest.

\section{Acknowledgments}

This work was supported by the National Natural Science Foundation of China (51476094 and 51590902) and the outstanding youth project of Hunan Provincial Education Department (no. 16B236).

\section{References}

[1] A. L. Moore and L. Shi, "Emerging challenges and materials for thermal management of electronics," Materials Today, vol. 17, no. 4, pp. 163-174, 2014.

[2] Z. Yan, G. Liu, J. M. Khan, and A. A. Balandin, "Graphene quilts for thermal management of high-power GaN transistors," Nature Communications, vol. 3, article 827, 2012.

[3] Y. Deng and J. Liu, "A liquid metal cooling system for the thermal management of high power LEDs," International Communications in Heat and Mass Transfer, vol. 37, no. 7, pp. 788-791, 2010.

[4] X. Duan and G. F. Naterer, "Heat transfer in phase change materials for thermal management of electric vehicle battery modules," International Journal of Heat and Mass Transfer, vol. 53, no. 23-24, pp. 5176-5182, 2010.

[5] N. Putra and B. Ariantara, "Electric motor thermal management system using L-shaped flat heat pipes," Applied Thermal Engineering, 2016.

[6] K. M. F. Shahil and A. A. Balandin, "Thermal properties of graphene and multilayer graphene: applications in thermal interface materials," Solid State Communications, vol. 152, no. 15, pp. 1331-1340, 2012.

[7] A. J. McNamara, Y. Joshi, and Z. M. Zhang, "Characterization of nanostructured thermal interface materials - A review," International Journal of Thermal Sciences, vol. 62, pp. 2-11, 2012.
[8] V. Goyal and A. A. Balandin, "Thermal properties of the hybrid graphene-metal nano-micro-composites: applications in thermal interface materials," Applied Physics Letters, vol. 100, Article ID 073113, 2012.

[9] Y. Xuan and Q. Li, "Heat transfer enhancement of nanofluids," International Journal of Heat and Fluid Flow, vol. 21, no. 1, pp. 58-64, 2000.

[10] Y. Xuan and W. Roetzel, "Conceptions for heat transfer correlation of nanofluids," International Journal of Heat and Mass Transfer, vol. 43, no. 19, pp. 3701-3707, 2000.

[11] J. Buongiorno, “Convective transport in nanofluids," Journal of Heat Transfer, vol. 128, no. 3, pp. 240-250, 2006.

[12] A. Mills, M. Farid, J. R. Selman, and S. Al-Hallaj, "Thermal conductivity enhancement of phase change materials using a graphite matrix," Applied Thermal Engineering, vol. 26, no. 14-15, pp. 1652-1661, 2006.

[13] L. Fan and J. M. Khodadadi, "Thermal conductivity enhancement of phase change materials for thermal energy storage: A review," Renewable and Sustainable Energy Reviews, vol. 15, no. 1, pp. 24-46, 2011.

[14] S. Kim and L. T. Drzal, "High latent heat storage and high thermal conductive phase change materials using exfoliated graphite nanoplatelets," Solar Energy Materials and Solar Cells, vol. 93, no. 1, pp. 136-142, 2009.

[15] Z. Liqun, G. Haiping, Z. Hong et al., "Advances in study of thermal-conductive polymers," China Synthetic Rubber Industry, vol. 1, 1998.

[16] L. M. Zhang and G. C. Dai, "Effect of interfacial treatment on the thermal properties of thermal conductive plastics," Express Polymer Letters, vol. 1, no. 9, pp. 608-615, 2007.

[17] J. Xu and T. S. Fisher, "Enhancement of thermal interface materials with carbon nanotube arrays," International Journal of Heat and Mass Transfer, vol. 49, no. 9-10, pp. 1658-1666, 2006.

[18] D. Suh, C. M. Moon, D. Kim, and S. Baik, "Ultrahigh Thermal Conductivity of Interface Materials by Silver-Functionalized Carbon Nanotube Phonon Conduits," Advanced Materials, pp. 7220-7227, 2016. 
[19] M. Hemmat Esfe, S. Saedodin, W.-M. Yan, M. Afrand, and N. Sina, "Study on thermal conductivity of water-based nanofluids with hybrid suspensions of CNTs/Al2O3 nanoparticles," Journal of Thermal Analysis and Calorimetry, vol. 124, no. 1, pp. 455-460, 2016.

[20] H. Li, L. Wang, Y. He, Y. Hu, J. Zhu, and B. Jiang, "Experimental investigation of thermal conductivity and viscosity of ethylene glycol based $\mathrm{ZnO}$ nanofluids," Applied Thermal Engineering, vol. 88, pp. 363-368, 2014.

[21] P. Goli, S. Legedza, A. Dhar, R. Salgado, J. Renteria, and A. A. Balandin, "Graphene-enhanced hybrid phase change materials for thermal management of Li-ion batteries," Journal of Power Sources, vol. 248, pp. 37-43, 2014.

[22] M. Z. Wang, X. Xing, and W. Yu, "The progress of graphene in thermal transportation," Advanced Materials Research, vol. 1039, pp. 438-445, 2014.

[23] W. Yu, H. Xie, L. Chen, Z. Zhu, J. Zhao, and Z. Zhang, "Graphene based silicone thermal greases," Physics Letters, Section A: General, Atomic and Solid State Physics, vol. 378, no. 3, pp. 207211, 2014.

[24] W. Yu, H. Xie, F. Li, J. Zhao, and Z. Zhang, "Significant thermal conductivity enhancement in graphene oxide papers modified with alkaline earth metal ions," Applied Physics Letters, vol. 103, no. 14, Article ID 141913, 2013.

[25] K. Uetani, S. Ata, S. Tomonoh, T. Yamada, M. Yumura, and K. Hata, "Elastomeric thermal interface materials with high through-plane thermal conductivity from carbon fiber fillers vertically aligned by electrostatic flocking," Advanced Materials, vol. 26, no. 33, pp. 5857-5862, 2014.

[26] H. Wang, J. Gong, Y. Pei, and Z. Xu, “Thermal transfer in graphene-interfaced materials: Contact resistance and interface engineering," ACS Applied Materials and Interfaces, vol. 5, no. 7, pp. 2599-2603, 2013.

[27] X. Li, C. Zou, X. Lei, and W. Li, "Stability and enhanced thermal conductivity of ethylene glycol-based SiC nanofluids," International Journal of Heat and Mass Transfer, vol. 89, pp. 613619, 2015.

[28] R. H. Davis, "The effective thermal conductivity of a composite material with spherical inclusions," International Journal of Thermophysics, vol. 7, no. 3, pp. 609-620, 1986.

[29] Z. M. Zhang, Nano/Microscale Heat Transfer, Nanoscience and Nanotechnology Series, McGraw Hill, New York, NY, USA, 2007.

[30] W. Yu, M. Wang, H. Xie, Y. Hu, and L. Chen, "Silicon carbide nanowires suspensions with high thermal transport properties," Applied Thermal Engineering, vol. 94, pp. 350-354, 2016.

[31] H. Xie, J. Wang, T. Xi, Y. Liu, F. Ai, and Q. Wu, “Thermal conductivity enhancement of suspensions containing nanosized alumina particles," Journal of Applied Physics, vol. 91, no. 7, pp. 4568-4572, 2002.

[32] P. Warrier and A. Teja, "Effect of particle size on the thermal conductivity of nanofluids containing metallic nanoparticles," Nanoscale Research Letters, vol. 6, no. 1, pp. X1-6, 2011.

[33] P. Nath and K. L. Chopra, "Thermal conductivity of copper films," Thin Solid Films, vol. 20, no. 1, pp. 53-62, 1974.

[34] K. Pashayi, H. R. Fard, F. Lai, S. Iruvanti, J. Plawsky, and T. Borca-Tasciuc, "High thermal conductivity epoxy-silver composites based on self-constructed nanostructured metallic networks," Journal of Applied Physics, vol. 111, no. 10, Article ID 104310, 2012.
[35] W. Yu, D. M. France, J. L. Routbort, and S. U. S. Choi, "Review and comparison of nanofluid thermal conductivity and heat transfer enhancements," Heat Transfer Engineering, vol. 29, no. 5, pp. 432-460, 2008.

[36] M. P. Beck, Y. Yuan, P. Warrier, and A. S. Teja, "The effect of particle size on the thermal conductivity of alumina nanofluids," Journal of Nanoparticle Research, vol. 11, no. 5, pp. 1129-1136, 2009.

[37] W.-Q. Lu and Q.-M. Fan, "Study for the particle's scale effect on some thermophysical properties of nanofluids by a simplified molecular dynamics method," Engineering Analysis with Boundary Elements, vol. 32, no. 4, pp. 282-289, 2008.

[38] G. Chen, W. Yu, D. Singh, D. Cookson, and J. Routbort, "Application of SAXS to the study of particle-size-dependent thermal conductivity in silica nanofluids," Journal of Nanoparticle Research, vol. 10, no. 7, pp. 1109-1114, 2008.

[39] E. V. Timofeeva, D. S. Smith, W. Yu, D. M. France, D. Singh, and J. L. Routbort, "Particle size and interfacial effects on thermophysical and heat transfer characteristics of water-based $\alpha$-SiC nanofluids," Nanotechnology, vol. 21, no. 21, pp. 215703-215710, 2010.

[40] H. S. Tekce, D. Kumlutas, and I. H. Tavman, "Effect of particle shape on thermal conductivity of copper reinforced polymer composites," Journal of Reinforced Plastics and Composites, vol. 26, no. 1, pp. 113-121, 2007.

[41] M. Hemmat Esfe, S. Saedodin, S. Wongwises, and D. Toghraie, "An experimental study on the effect of diameter on thermal conductivity and dynamic viscosity of Fe/water nanofluids," Journal of Thermal Analysis and Calorimetry, vol. 119, no. 3, pp. 1817-1824, 2015.

[42] W. Yu, J. Zhao, M. Wang, Y. Hu, L. Chen, and H. Xie, “Thermal conductivity enhancement in thermal grease containing different CuO structures," Nanoscale Research Letters, vol. 10, no. 1, pp. 1-8, 2015.

[43] H. Du, Y. Qi, W. Yu, J. Yin, and H. Xie, “T-shape ZnO whisker: a more effective thermal conductive filler than spherical particles for the thermal grease," International Journal of Heat and Mass Transfer, vol. 112, pp. 1052-1056, 2017.

[44] D. Chauhan, N. Singhvi, and R. Singh, "Effect of geometry of filler particles on the effective thermal conductivity of twophase systems," International Journal of Modern Nonlinear Theory and Application, vol. 01, no. 02, pp. 40-46, 2012.

[45] S. Berber, Y.-K. Kwon, and D. Tománek, "Unusually high thermal conductivity of carbon nanotubes," Physical Review Letters, vol. 84, no. 20, pp. 4613-4616, 2000.

[46] M. Fujii, X. Zhang, H. Xie et al., "Measuring the thermal conductivity of a single carbon nanotube," Physical Review Letters, vol. 95, no. 6, Article ID 065502, 2005.

[47] Q. Li, C. Liu, X. Wang, and S. Fan, "Measuring the thermal conductivity of individual carbon nanotubes by the Raman shift method," Nanotechnology, vol. 20, no. 14, Article ID 145702, 2009.

[48] M. T. Pettes and L. Shi, "Thermal and structural characterizations of individual single-, double-, and multi-walled carbon nanotubes," Advanced Functional Materials, vol. 19, no. 24, pp. 3918-3925, 2009.

[49] A. Nasiri, M. Shariaty-Niasar, A. M. Rashidi, and R. Khodafarin, "Effect of CNT structures on thermal conductivity and stability of nanofluid," International Journal of Heat and Mass Transfer, vol. 55, no. 5-6, pp. 1529-1535, 2012.

[50] M. Russ, S. S. Rahatekar, K. Koziol, B. Farmer, and H.-X. Peng, "Length-dependent electrical and thermal properties of carbon 
nanotube-loaded epoxy nanocomposites," Composites Science and Technology, vol. 81, pp. 42-47, 2013.

[51] M. James Clerk, "A treatise on electricity and magnetism," $A$ Treatise on Electricity and Magnetism, pp. 1-442, 2010.

[52] R. L. Hamilton and O. K. Crosser, "Thermal conductivity of heterogeneous two-component systems," Industrial and Engineering Chemistry Fundamentals, vol. 1, no. 3, pp. 187-191, 1962.

[53] B. Gu, B. Hou, Z. Lu, Z. Wang, and S. Chen, "Thermal conductivity of nanofluids containing high aspect ratio fillers," International Journal of Heat and Mass Transfer, vol. 64, pp. 108-114, 2013.

[54] E. Yamada and T. Ota, "Effective thermal conductivity of dispersed materials," Wärme- und Stoffübertragung, vol. 13, no. 12, pp. 27-37, 1980.

[55] D. Zhu, W. Yu, H. Du, L. Chen, Y. Li, and H. Xie, “Thermal Conductivity of Composite Materials Containing Copper Nanowires," Journal of Nanomaterials, vol. 2016, Article ID 3089716, 2016.

[56] B. Pal, S. S. Mallick, and B. Pal, "Anisotropic $\mathrm{CuO}$ nanostructures of different size and shape exhibit thermal conductivity superior than typical bulk powder," Colloids and Surfaces A: Physicochemical and Engineering Aspects, vol. 459, pp. 282-289, 2014.

[57] X. Fang, Q. Ding, L.-W. Fan, H. Lu, and Z.-T. Yu, "Effects of inclusion size on thermal conductivity and rheological behavior of ethylene glycol-based suspensions containing silver nanowires with various specific surface areas," International Journal of Heat and Mass Transfer, vol. 81, pp. 554-562, 2015.

[58] I. Seshadri, G. L. Esquenazi, T. Cardinal, T. Borca-Tasciuc, and G. Ramanath, "Microwave synthesis of branched silver nanowires and their use as fillers for high thermal conductivity polymer composites," Nanotechnology, vol. 27, no. 17, Article ID 175601, 2016.

[59] W. J. Evans, L. Hu, and P. Keblinski, “Thermal conductivity of graphene ribbons from equilibrium molecular dynamics: Effect of ribbon width, edge roughness, and hydrogen termination," Applied Physics Letters, vol. 96, no. 20, Article ID 203112, 2010.

[60] D. L. Nika, E. P. Pokatilov, and A. A. Balandin, “Theoretical description of thermal transport in graphene: The issues of phonon cut-off frequencies and polarization branches," Physica Status Solidi (B) Basic Research, vol. 248, no. 11, pp. 2609-2614, 2011.

[61] A. A. Balandin, S. Ghosh, W. Bao et al., "Superior thermal conductivity of single-layer graphene," Nano Letters, vol. 8, pp. 902-907, 2008.

[62] S. Ghosh, I. Calizo, D. Teweldebrhan et al., "Extremely high thermal conductivity of graphene: prospects for thermal management applications in nanoelectronic circuits," Applied Physics Letters, vol. 92, Article ID 151911, 2008.

[63] W. Cai, A. L. Moore, Y. Zhu et al., "Thermal transport in suspended and supported monolayer graphene grown by chemical vapor deposition," Nano Letters, vol. 10, no. 5, pp. 1645-1651, 2010.

[64] S. Chen, A. L. Moore, W. Cai et al., "Raman measurements of thermal transport in suspended monolayer graphene of variable sizes in vacuum and gaseous environments," ACS Nano, vol. 5, no. 1, pp. 321-328, 2011.

[65] W. Yu, H. Xie, and D. Bao, "Enhanced thermal conductivities of nanofluids containing graphene oxide nanosheets," Nanotechnology, vol. 21, no. 5, Article ID 055705, 2010.

[66] W. Yu, H. Xie, and W. Chen, "Experimental investigation on thermal conductivity of nanofluids containing graphene oxide nanosheets," Journal of Applied Physics, vol. 107, no. 9, Article ID 094317, 2010.

[67] S. G. Prolongo, A. Jiménez-Suárez, R. Moriche, and A. Ureña, "Graphene nanoplatelets thickness and lateral size influence on the morphology and behavior of epoxy composites," European Polymer Journal, vol. 53, no. 1, pp. 292-301, 2014.

[68] W. Yu, H. Xie, X. Wang, and X. Wang, "Significant thermal conductivity enhancement for nanofluids containing graphene nanosheets," Physics Letters, Section A: General, Atomic and Solid State Physics, vol. 375, no. 10, pp. 1323-1328, 2011.

[69] B. Tang, G. Hu, H. Gao, and L. Hai, "Application of graphene as filler to improve thermal transport property of epoxy resin for thermal interface materials," International Journal of Heat and Mass Transfer, vol. 85, pp. 420-429, 2015.

[70] Z. Kuang, Y. Chen, Y. Lu et al., "Fabrication of highly oriented hexagonal boron nitride nanosheet/elastomer nanocomposites with high thermal conductivity," Small, vol. 11, no. 14, pp. 16551659, 2015.

[71] X. Wang, A. Pakdel, J. Zhang et al., "Large-surface-area BN nanosheets and their utilization in polymeric composites with improved thermal and dielectric properties," Nanoscale Research Letters, vol. 7, 2012.

[72] D. Zhu, Y. Qi, W. Yu, L. Chen, M. Wang, and H. Xie, "Enhanced thermal conductivity for graphene nanoplatelets/epoxy resin composites," Journal of Thermal Science and Engineering Applications, vol. 10, no. 1, p. 011011, 2018.

[73] W. Yu, H. Xie, X. Zhou, Y. Li, and L. Chen, "Intriguingly high thermal conductivity enhancement of graphene nanoplatelets contained poly(methylmethacrylate) composites," in Proceedings of the The 15th International Heat Transfer Conference, Kyoto, Japan, August 2014.

[74] K. M. F. Shahil and A. A. Balandin, "Graphene-multilayer graphene nanocomposites as highly efficient thermal interface materials," Nano Letters, vol. 12, no. 2, pp. 861-867, 2012.

[75] Q. Song, M. An, X. Chen, Z. Peng, J. Zang, and N. Yang, "Adjustable thermal resistor by reversibly folding a graphene sheet," Nanoscale, vol. 8, no. 32, pp. 14943-14949, 2016.

[76] M. An, Q. Song, and X. Yu, "Generalized two-temperature model for coupled phonons," 2017, https://arxiv.org/abs/1702 .05237 .

[77] L. Chen, Y.-Y. Sun, H.-F. Xu et al., "Analytic modeling for the anisotropic thermal conductivity of polymer composites containing aligned hexagonal boron nitride," Composites Science and Technology, vol. 122, pp. 42-49, 2016.

[78] A. Yu, P. Ramesh, M. E. Itkis, E. Bekyarova, and R. C. Haddon, "Graphite nanoplatelet-epoxy composite thermal interface materials," Journal of Physical Chemistry C, vol. 111, no. 21, pp. 7565-7569, 2007.

[79] W. Zhou, S. Qi, C. Tu, H. Zhao, C. Wang, and J. Kou, "Effect of the particle size of $\mathrm{Al} 2 \mathrm{O} 3$ on the properties of filled heatconductive silicone rubber," Journal of Applied Polymer Science, vol. 104, no. 2, pp. 1312-1318, 2007.

[80] W.-Y. Zhou, S.-H. Qi, H.-Z. Zhao, and N.-L. Liu, “Thermally conductive silicone rubber reinforced with boron nitride particle," Polymer Composites, vol. 28, no. 1, pp. 23-28, 2007.

[81] W. Zhou, D. Yu, C. Wang, Q. An, and S. Qi, "Effect of filler size distribution on the mechanical and physical properties of alumina-filled silicone rubber," Polymer Engineering and Science, vol. 48, no. 7, pp. 1381-1388, 2008.

[82] Y. Zhang, W. Yu, L. Zhang, J. Yin, J. Wang, and H. Xie, “Thermal conductivity and mechanical properties of low density silicone 
rubber filled with $\mathrm{Al} 2 \mathrm{O} 3$ and graphene nanoplatelets," Journal of Thermal Science and Engineering Applications, vol. 10, no. 1, p. 011014, 2018.

[83] W. Yu, H. Xie, L. Yin, J. Zhao, L. Xia, and L. Chen, "Exceptionally high thermal conductivity of thermal grease: synergistic effects of graphene and alumina," International Journal of Thermal Sciences, vol. 91, article 4346, pp. 76-82, 2015.

[84] J. H. Kim, T. D. Dao, and H. M. Jeong, "Aluminum hydroxideCNT hybrid material for synergizing the thermal conductivity of alumina sphere/thermoplastic polyurethane composite with minimal increase of electrical conductivity," Journal of Industrial and Engineering Chemistry, vol. 33, pp. 150-155, 2016.

[85] J. Jiao, Y. Cui, and Y. Xia, "Improved thermal conductivity of epoxy composites prepared with a mixed filler of multiwalled carbon nanotubes and aluminum nitride particles," High Performance Polymers, vol. 29, no. 4, pp. 484-492, 2016.

[86] L. Chen, H. Xie, and W. Yu, "Multi-walled carbon nanotube/ silver nanoparticles used for thermal transportation," Journal of Materials Science, vol. 47, no. 14, pp. 5590-5595, 2012.

[87] N. Jha and S. Ramaprabhu, "Synthesis and thermal conductivity of copper nanoparticle decorated multiwalled carbon nanotubes based nanofluids," Journal of Physical Chemistry C, vol. 112, no. 25, pp. 9315-9319, 2008.

[88] R. Qian, J. Yu, C. Wu, X. Zhai, and P. Jiang, "Alumina-coated graphene sheet hybrids for electrically insulating polymer composites with high thermal conductivity," RSC Advances, vol. 3, no. 38, pp. 17373-17379, 2013.

[89] W. Yu, Y. Qi, Y. Zhou, L. Chen, H. Du, and H. Xie, "Synergistic improvement of thermal transport properties for thermoplastic composites containing mixed alumina and graphene fillers," Journal of Applied Polymer Science, vol. 133, no. 13, Article ID 43242, 2016.

[90] L. Chen, P. Zhao, H. Xie, and W. Yu, “Thermal properties of epoxy resin based thermal interfacial materials by filling $\mathrm{Ag}$ nanoparticle-decorated graphene nanosheets," Composites Science and Technology, vol. 125, pp. 17-21, 2016.

[91] F. Wang, X. Zeng, Y. Yao, R. Sun, J. Xu, and C.-P. Wong, "Silver Nanoparticle-Deposited Boron Nitride Nanosheets as Fillers for Polymeric Composites with High Thermal Conductivity," Scientific Reports, vol. 6, Article ID 19394, 2016.

[92] S. S. J. Aravind and S. Ramaprabhu, "Graphene-multiwalled carbon nanotube-based nanofluids for improved heat dissipation," RSC Advances, vol. 3, no. 13, pp. 4199-4206, 2013.

[93] J. Che, K. Wu, Y. Lin, K. Wang, and Q. Fu, "Largely improved thermal conductivity of HDPE/expanded graphite/carbon nanotubes ternary composites via filler network-network synergy," Composites Part A: Applied Science and Manufacturing, vol. 99, pp. 32-40, 2017.

[94] M. Wegrzyn, B. Galindo, A. Benedito, and E. Gimenez, "Morphology, thermal, and electrical properties of polypropylene hybrid composites co-filled with multi-walled carbon nanotubes and graphene nanoplatelets," Journal of Applied Polymer Science, vol. 132, no. 46, Article ID 42793, 2015.

[95] Y. J. Noh and S. Y. Kim, "Synergistic improvement of thermal conductivity in polymer composites filled with pitch based carbon fiber and graphene nanoplatelets," Polymer Testing, vol. 45, pp. 132-138, 2015.

[96] A. Yu, P. Ramesh, X. Sun, E. Bekyarova, M. E. Itkis, and R. C. Haddon, "Enhanced thermal conductivity in a hybrid graphite nanoplatelet-carbon nanotube filler for epoxy composites," Advanced Materials, vol. 20, no. 24, pp. 4740-4744, 2008.
[97] H. Im and J. Kim, “Thermal conductivity of a graphene oxidecarbon nanotube hybrid/epoxy composite," Carbon, vol. 50, no. 15, pp. 5429-5440, 2012.

[98] J. Su, Y. Xiao, and M. Ren, "Enhanced thermal conductivity in epoxy nanocomposites with hybrid boron nitride nanotubes and nanosheets," Physica Status Solidi (A) Applications and Materials Science, vol. 210, no. 12, pp. 2699-2705, 2013.

[99] H. Yan, Y. Tang, J. Su, and X. Yang, "Enhanced thermal-mechanical properties of polymer composites with hybrid boron nitride nanofillers," Applied Physics A: Materials Science and Processing, vol. 114, no. 2, pp. 331-337, 2014. 

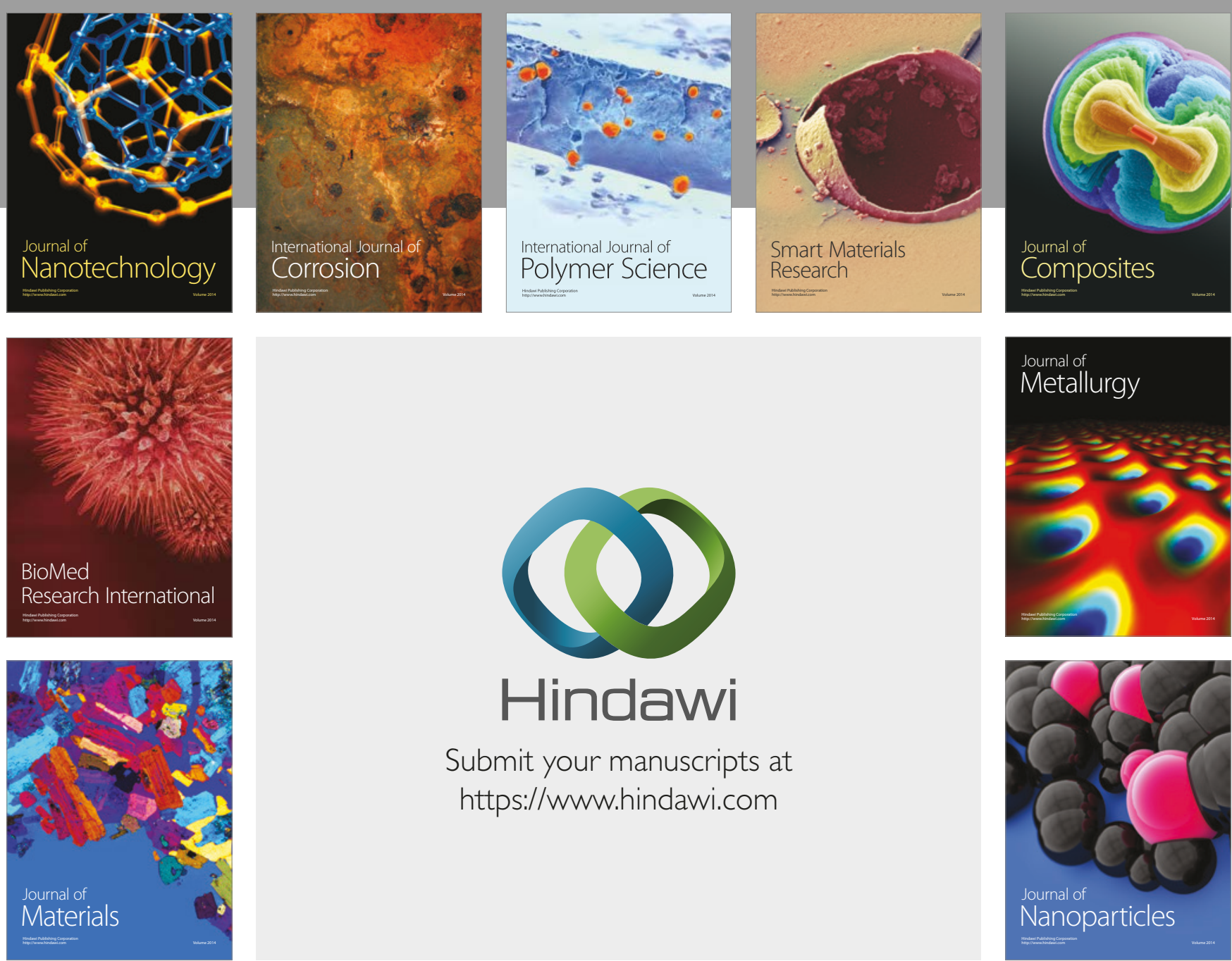

\section{Hindawi}

Submit your manuscripts at

https://www.hindawi.com
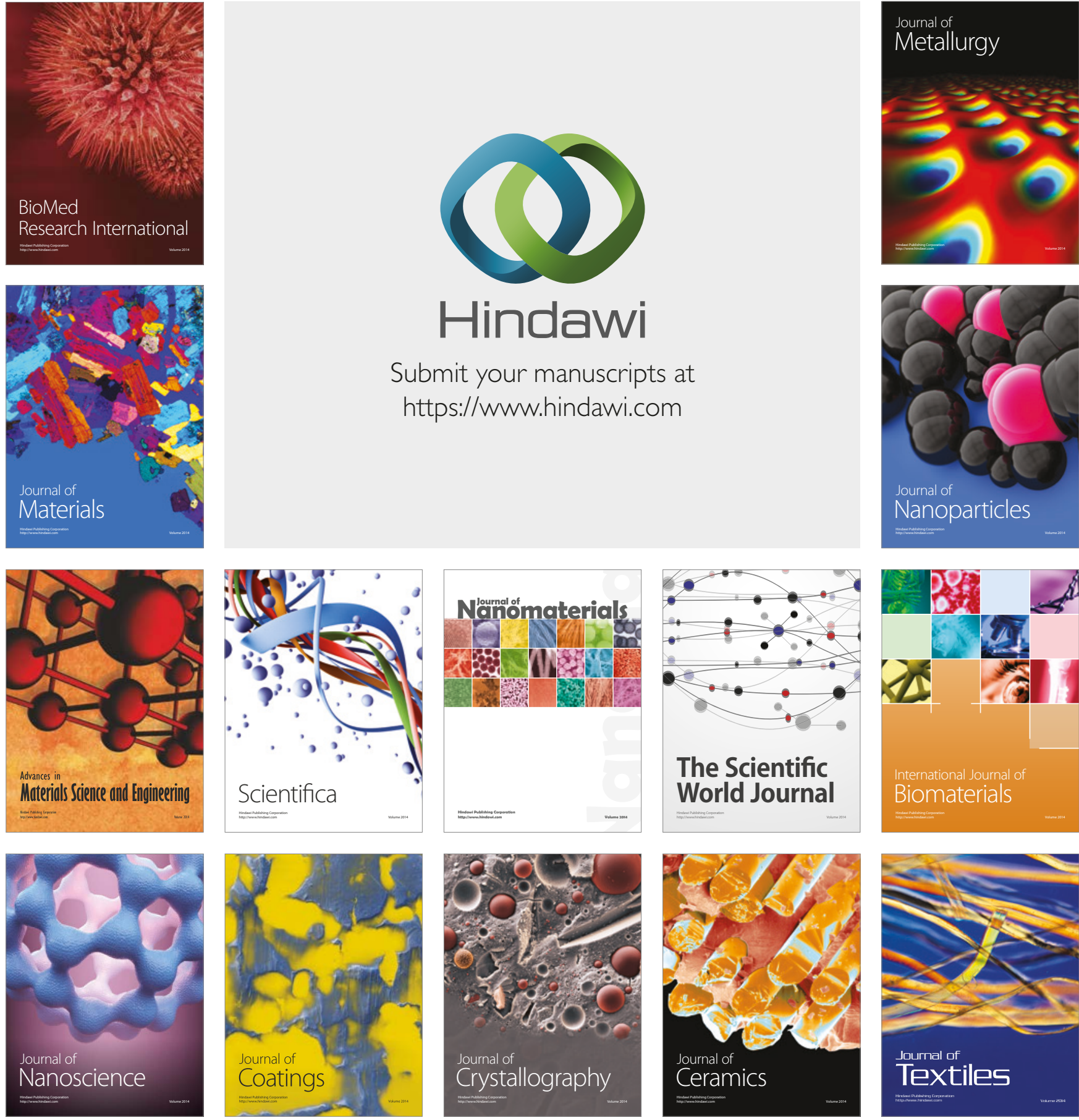

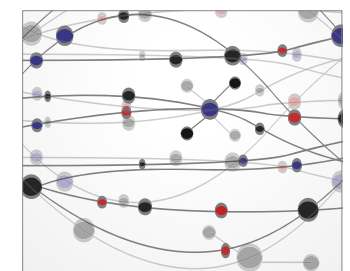

The Scientific World Journal
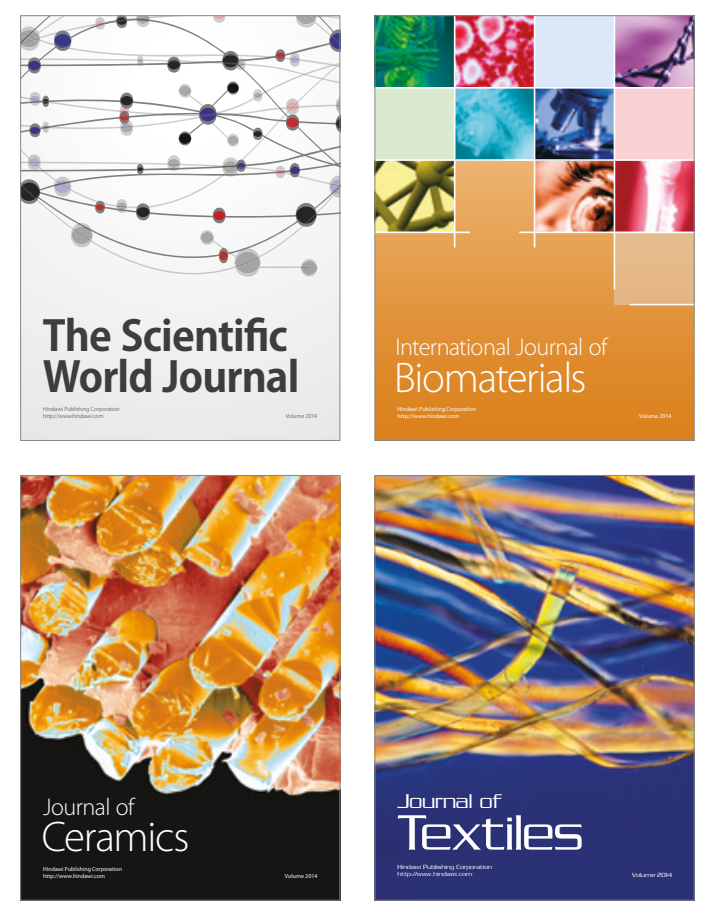